\title{
تطور العلاقة بين إستعمالات الأرض الحضرية والسكان في مدينة زاخو وفق المراحل المورفولوجية 1947- 2017
}

\author{
جهان هاشم مُحَّمَ و نشوان شكري عبد الله

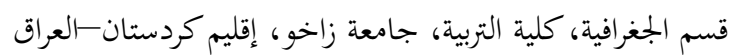

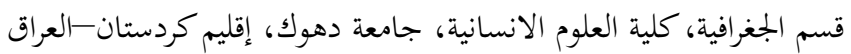 \\ (تاريخ استلام البحث:5 أيار، 2020، تاريخ القبول بالنشر: 20 اليار، 2020)
}

الخلاصة

تعد مدينة زاخو ضمن المدن التي شهدت نمواً سريعاً في المساحة والسكان ، فمن خلال تتبع المراحل المورفولوجية قبل 1947 فئل 1947 وحتى

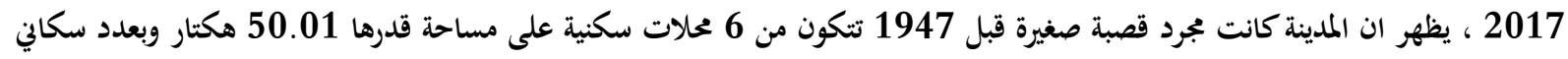

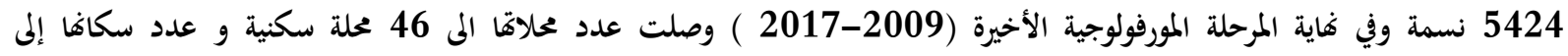

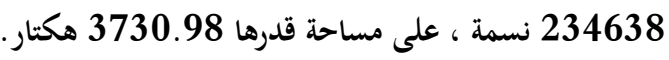

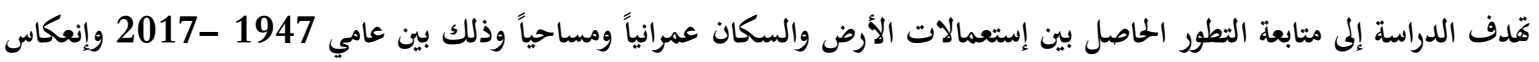

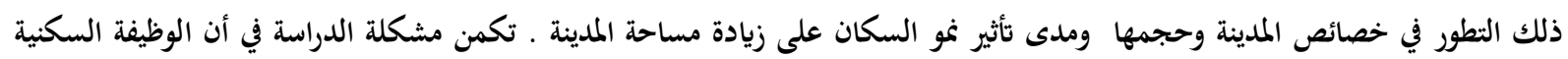

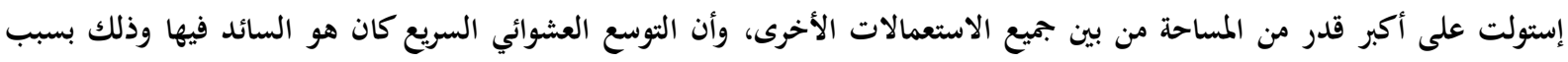

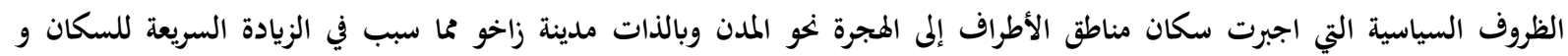

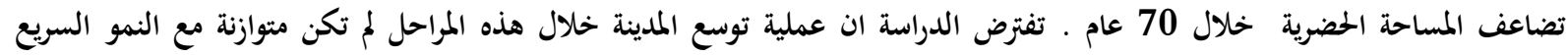

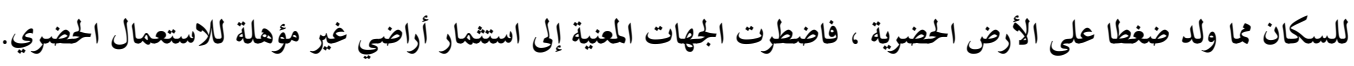

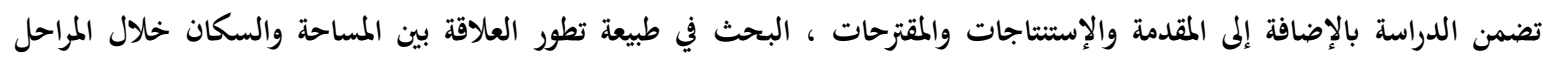

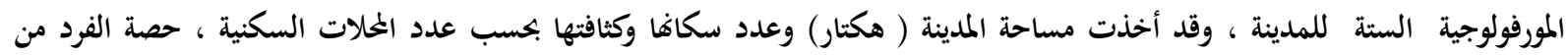
المساحة كمثغيرات للتمييز بين المراحل الستة.

الكلمات الدالة : المدينة ، المرحلة المورفولوجية ، السكان ، الأرض الحضرية، التوسع الحضري

الواسع كانت أحد متطلبات الموضع المناسب لنشأة مدينة

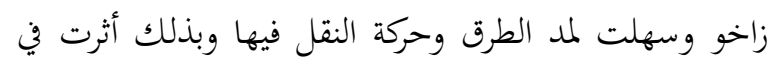

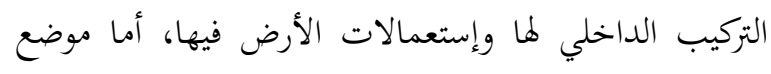
المدينة على ضفاف غر الخابور أثر في بنيتها الداخلية وشكلها

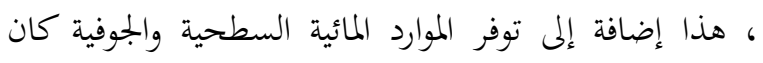

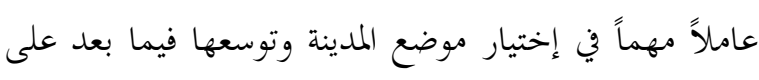

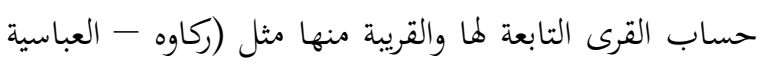

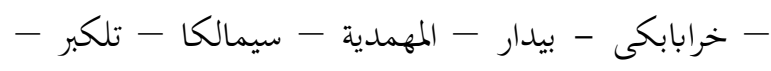
شكفتمارا - ده شت مر - آفرما - سه لكا ) وحالياً جميعها لهابها

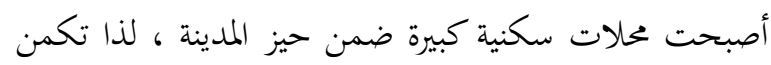

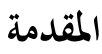

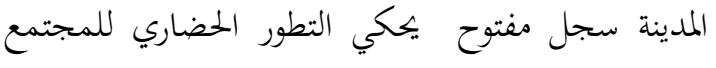
الذي يشغل مساحتها ، لذا يعتبر المساحة أبرز متغير ثم نمط

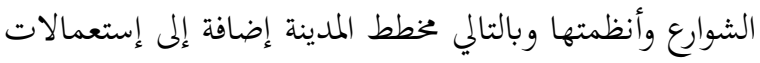

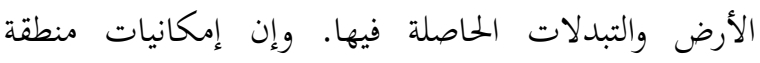
الدراسة الذاتية لها دور مهم في نمو مدينة زاخو وتطورها

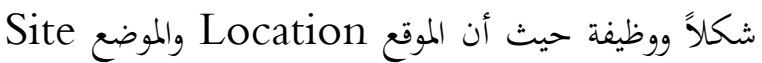
كانتا من العوامل الجغرافية الطبيعية عملت بصورة متفاعلة في نشأتها، فالموقع أثر في حجم ومساحة المدينة ونشاطها الأقتصادي ، والموضع أثر في نشأتما ، فوجود السهل السندي jhannaseam@yahoo.com 
والإستنتاجات والمقترحات وبالإعتماد على الدراسات التاريخية والميدانية قسمت الدراسة إلى ستة مراحل مورفولوجية وهي : :-

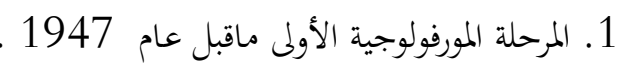

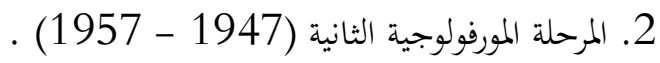

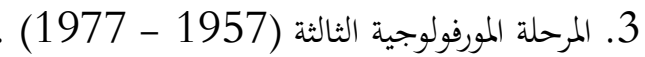

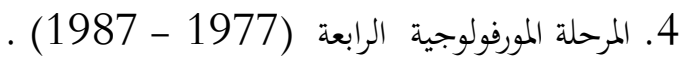
5. المرحلة المورفولوجية الخامسة (1987 - 2009) . 6. المرحلة المورفولوجية السادسة (2009 - 2017).

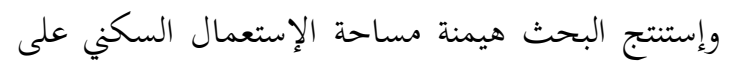
أكبر حصة مساحية خلال المراحل المورفولوجية الستة ،

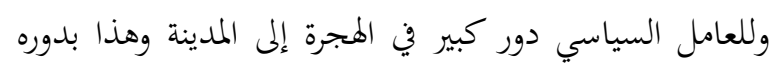

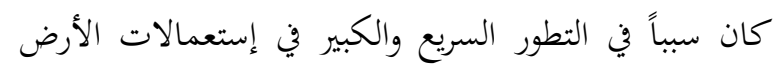
خلال الفترة ماقبل 1947 - 2017 .

\section{1. المرحلة المورفولوجية الأولى ماقبل عام 1947 العترهي} كانت زاخو قصبة "صغيرة على شكل جزيرة تحيط بها

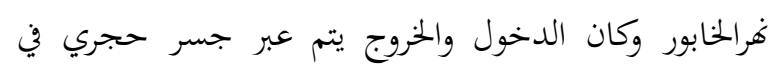

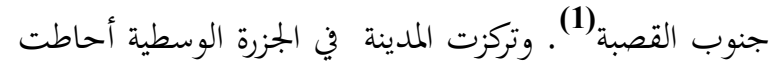
كما أراضي زراعية ديمية وأخرى إروائية لبساتين الفاكهة ، وخارج الجزرة الوسطية كانت خالية عدا محلة كيستة الأثرية

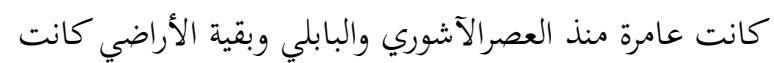

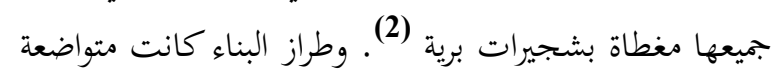

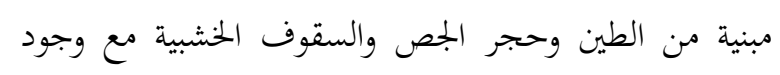
تخطيط بسيط مثل شارع رئيسي وجامع وسوق ضيق مترين ونعرج

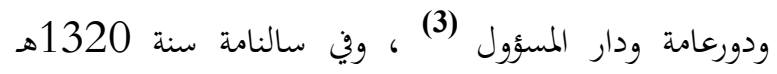
(1912م) وردت أن قصبة زاخو كانت تتسع بشكل تدريجي ودوري

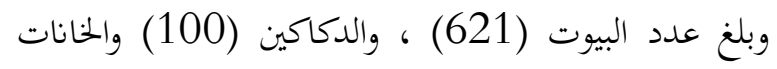

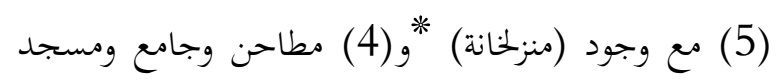
وكنيسة ومعبد يهودي ومدرسة دينية ومدرسة إبتدائية

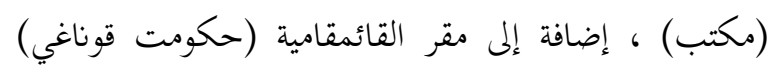

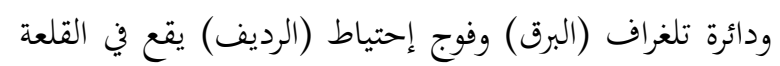
القديمة في الطرف الشمالي من القصبة(4). وفي عام 1925

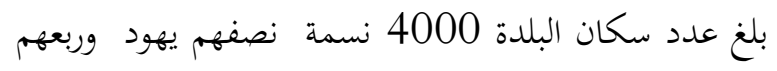

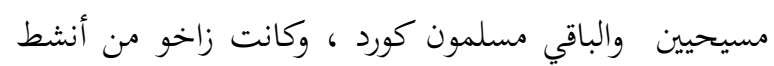

مشكلة البحث حول طبيعة تطورالعلاقة بين إستعمالات الحضرية والسكان في مدينة زاخو، وأثناء تطورالعلاقة أفرزت

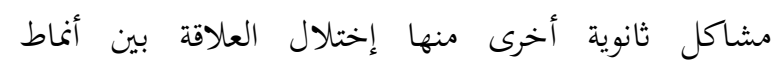

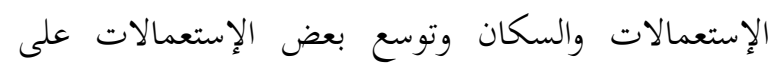
حساب إستعمالات أخرى . ويهدف البحث إلى دراسة ومتابعة التطور الحاصل بين

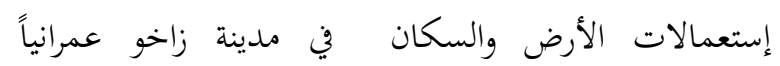
ومساحياً وذلك من فترة ماقبل عام 1947 وحتى فهاية

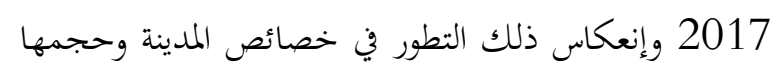
ومدى تأثير نمو وتوزيع السكان على زيادة مساحة المدينة خلال هذه الفترة ، وقد أخذت مساحة المدينة ( هكتار)

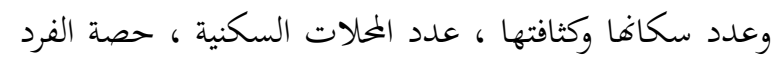
من المساحة كمتغيرات للتمييز بين المراحل المورفولوجية والتي تعمل مجتمعة لتحديد خصائص كل مرحلة ، وتفترض الدراسة مايلي :1-شهدت المدينة نمواً سريعاً للسكان والمساحة خلال فترة

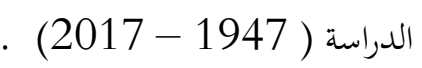
2- توسع أنماط معينة من الإستعمالات على حساب أنماط

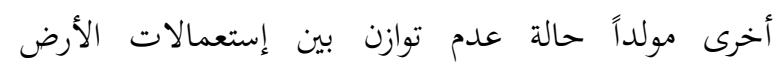
والسكان طوال فترة سنوات الدراسة . واجهت الباحثة مشكلة صعوبة الحصول على البيانات الرقمية التي تخص مساحة إستعمالات الأرض لذا تم قياسها

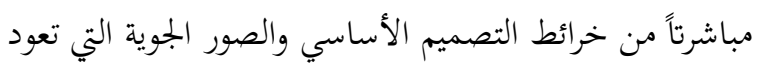

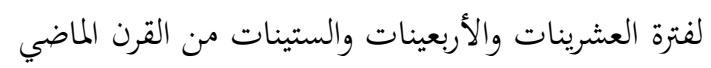
إضافة إلى المقابلات الشخصية من قبل المعنيين ( مهندسين ومساحين ) في رئاسة بلدية زاخو لسد النقص في البيانات المطلوبة والخصول على معلومات حقيقية قدر الإمكان، وكذلك تم مقابلة شخصيات معمرة للحصول على معلومات

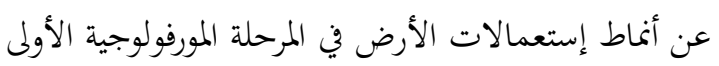

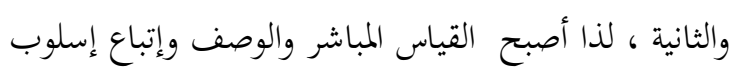

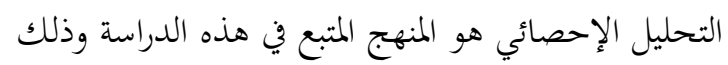
للتحقق من مدى صحة الفرضيات، وتضمن البحث المقدمة 
المدن في بادينان إقتصادياً حيث فيها أسباب الربح بالأخص كانت تضم تسعة محلات سكنية وهي (الكيستة ، محلة اليهود

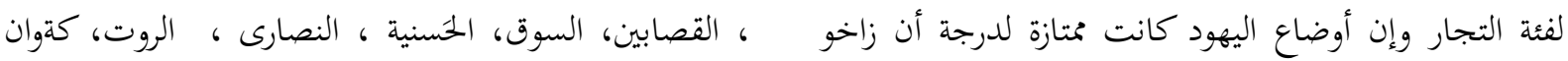
كانت قد سميت في المصادر العبرية بإسم (أوشليم كردستان ) ، الكندك. وخمسة منها كانت في الجزرة الوسطية والمحلات

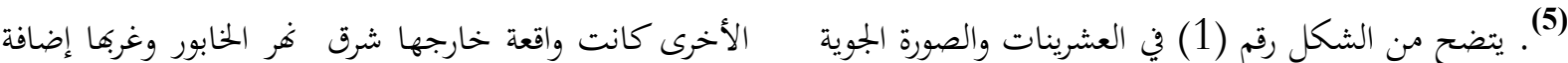

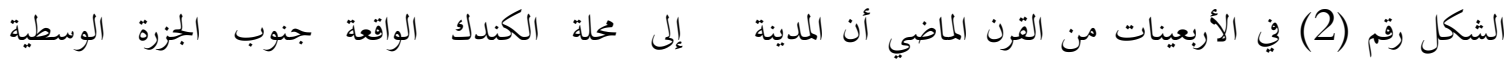
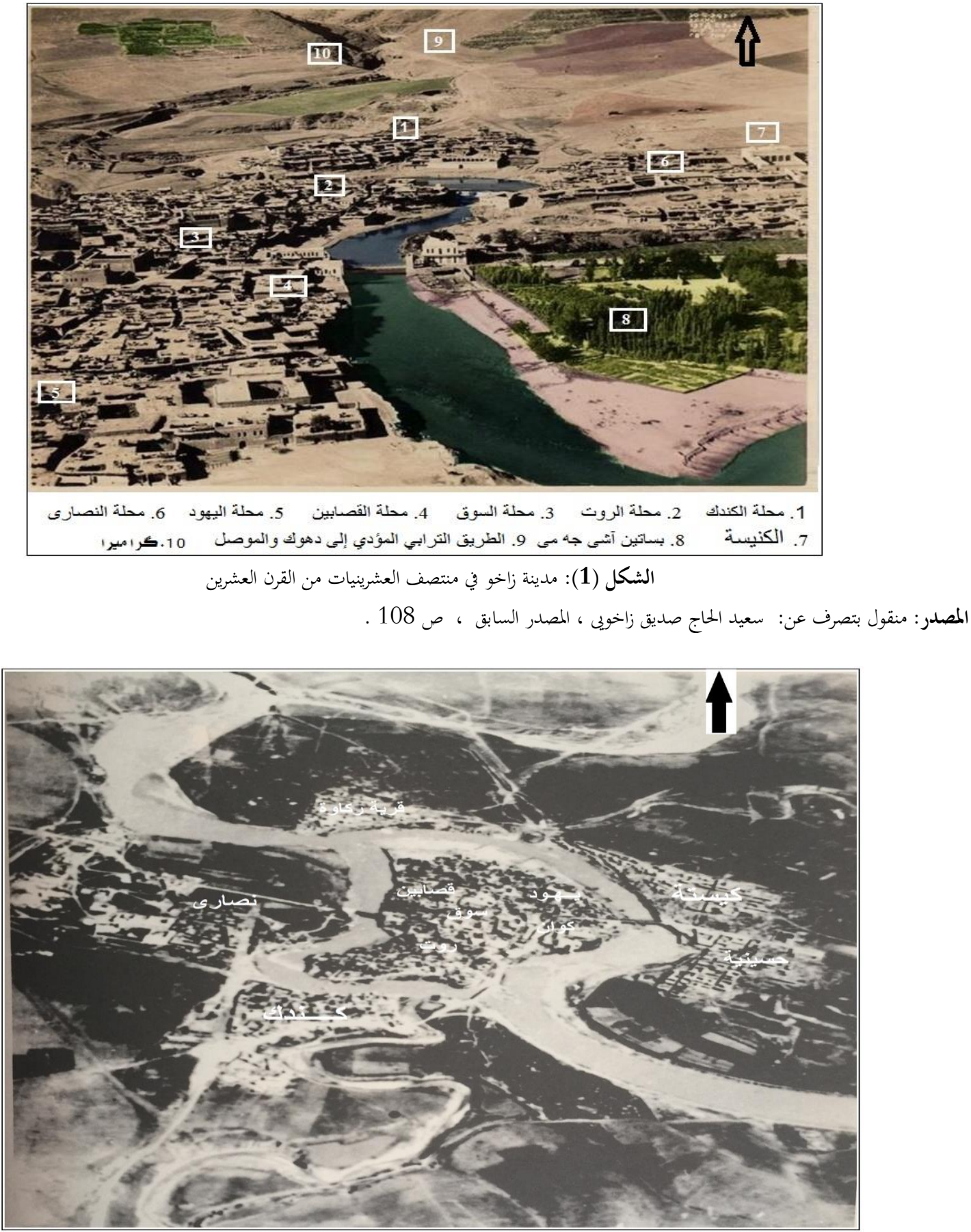

الشكل (2): صورة جوية لمدينة زاخو في منتصف الأرعينيات من القرن العشرين

Master Plan Zakho,(Urban Development, Sewerage and WWTP, Traffic) Urban development, October المصدر: 2013, page 22 
6. محلة كوان : بنيت بعد محلة الروت داخل الجزرة الوسطية

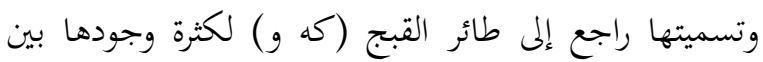
أحراش وشجيرات المنطقة ، وتقع جنوب محلة اليهود .

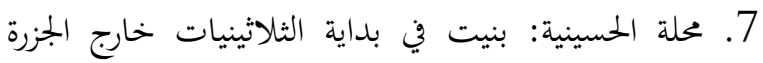
الوسطية على ضفاف غر الخابور شرقاً وتم بناؤها على أطلال حسنية الخابور التي دمرت عام 1041م ـ مانى 8. محلة النصارى: تقع خارج الجزرة الوسطية في الجهة الجنوبية الغربية لنهر الخابور، كانت ولازالت تسكنها العوائل المسيحية

9. محلة الكندك: تقع خارج الجزرة الوسطية جنوب غر المخابور، ومحلة سَيدوكا الواقعة شرقها كانت تابعة لمحلة الكندك لذا لم تذكر إسمها في إحصائيات السكان . لمانهان كان عدد سكان مدينة زاخو 5424 نسمة حسب لهب

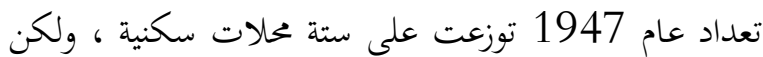
في الحقيقة كانت تضم تسع محلات ولكن في قوائم الإحصاءات كان يتم جمع عدد محلات مع بعضها تحت إسم

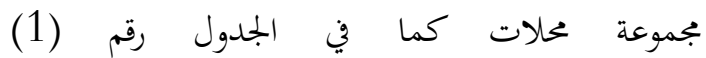

وفيما يلي تعريف لبعض محلات زاخو القديمة (6)

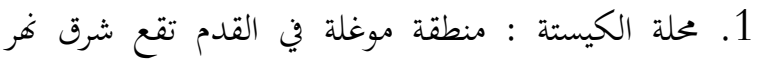
الخابور كانت عامرة في العصر الآشوري والبابلي و آثارها مدفونة تحت التراب ، وتسمى محلة الأرمن لإسكافم فيها بعد العدابع الهجوم العثماني عليهم في بداية العشرينات 2. محلة اليهود (آزادي) : بنيت داخل الجزرة الوسطية وعندها يلتقي الفرع الشرقي من النهر بالفرع الغربي وتسمى محلياً (خيزى دوو ئافي) ، ولا يعرف تاريخ بناء المحلة بالضبط واليهود هم البناة الأوائل ها. 3. محلة القصابين: جنوب غرب محلة اليهود وساكنيها كانوا

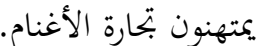
4. محلة السوق: جنوب محلة القصابين وهي أقرب المحلات إلى السوق لذا سميت بهذا الإسم . 5. محلة الروت: في الجزرة الوسطية جنوباً بنيت بعد محلة اليهود، القسم الجنوبي الشرقي منها تسمى بمحلة القرج ويعود تاريخ بناؤها إلى منتصف القرن التاسع عشر، وهي كانت تابعة لمحلة الروت، لذا لم يذكر إسمها في الإحصائيات السكانية

جدول (1): سكان ومساحة محلات مدينة زاخو عام 1947

\begin{tabular}{|c|c|c|c|c|c|c|}
\hline الكثافة السكانية & $\begin{array}{c}\text { النسبة المئوية } \\
\text { (\%) }\end{array}$ & المساحة & $\begin{array}{c}\text { النسبة المئوية } \\
\text { (\%) }\end{array}$ & عدد السكان & إسم الحلة & ت \\
\hline 313.2 & 12.83 & 4.710 & 27.19 & 1475 & اليهود & 1 \\
\hline 238.6 & 7.39 & 2.712 & 11.93 & 647 & الروت & 2 \\
\hline 65.7 & 33.53 & 12.306 & 14.92 & 809 & مجموعة محلات (كوان، & 3 \\
\hline 169.0 & 12.25 & 4.497 & 14.01 & 760 & الحسينية & 4 \\
\hline 70.8 & 28.06 & 10.297 & 13.44 & 729 & النصارى & 5 \\
\hline 461.6 & 5.93 & 2.175 & 18.51 & 1004 & الكندك & 6 \\
\hline 147.8 & 100 & 36.697 & 100 & 5424 & & \\
\hline
\end{tabular}

عمل الباحثة بالإعتماد على :-

1. حكومة إقليم كوردستان العراق ، وزارة البلديات ، رئاسة بلدية زاخو ، قسم

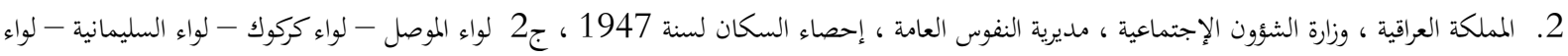

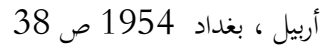

وبنسبة 18.51 \% و مساحتها 2.175 هكتار وبنسبة 5.93 أما المرتبة الثالثة فكانت من نصيب محلة الحسينية

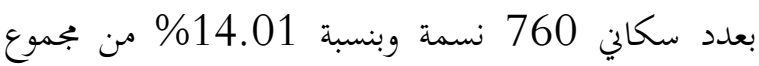
السكان، والبالغ مساحتها 4.497 هكتار وبنسبة وبنسة
إستحوذت محلة اليهود على المرتبة الأولى من حيث عدد

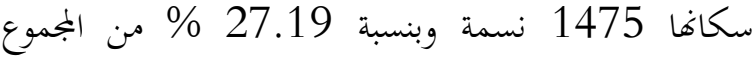
الكلي وعلى مساحة 4.710 هكتار بنسبة 12.28 \% وجاءت محلة الكندك في المرتبة الثانية البالغ عددهم 1004 
12.25\%. ولكن تأتي محلة النصارى في المرتبة الأولى من النقل 7.37 م2 ، وقد شغلت الخدمات العامة

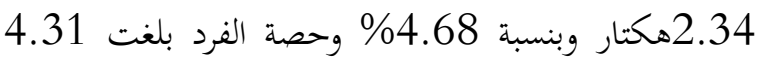

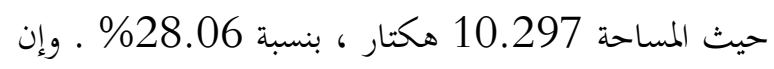
أسماء المحلات (كه وان ، السوق ، القصابين ، الكيستة) وكانت القلعة القديمة (القشلة) هي مجمع دوائر تضم مركزاً

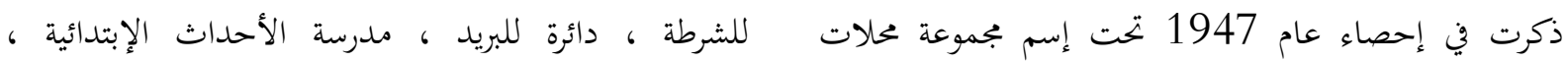

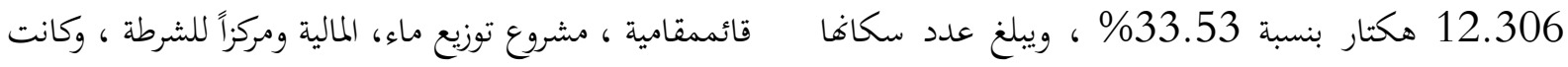
809 نسمة. لذا بلغت عدد السكان في هذه المرحلة 5424 م المدينة تضم (معطة وقود ، محطة كهرباء، دائرة كهرباء ، دائرة

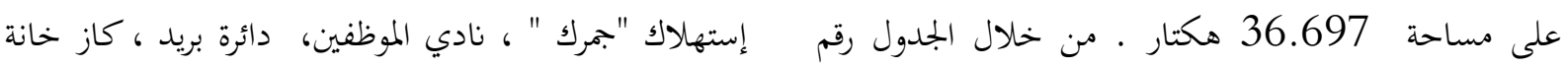

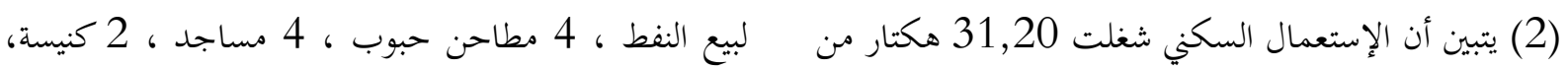
مساحة المعمور وبنسبة 62.93 \% وحصة الفرد بلغت كنيست اليهود) م2، أما بالنسبة للإستعمال التجاري شغلت

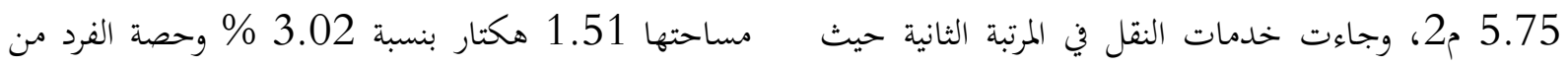

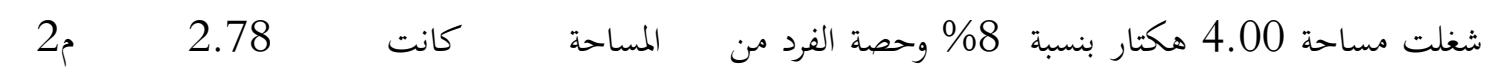

جدول (2): إستعمالات الأرض الحضرية وحصة الفرد منها في مدينة زاخو فاية المرحلة المورفولوجية الأولى عام 1947 الموام

\begin{tabular}{|c|c|c|c|c|}
\hline حصة الفرد من المساحة (م²) & $(\%)$ & المساحة (هكتار) & إستعمالات الأرض & ت \\
\hline 5.75 & 62.39 & 31.20 & سكني & 1 \\
\hline 2.78 & 3.02 & 1.51 & تجاري & 2 \\
\hline 7.37 & 8.00 & 4.00 & خدمات النقل & 3 \\
\hline 4.31 & 4.68 & 2.34 & خدمات عامة & 4 \\
\hline 0.09 & 1.00 & 0.50 & التعليمي & 5 \\
\hline 0.07 & 0.08 & 0.04 & الصحي & 6 \\
\hline 1.62 & 1.76 & 0.88 & الديني & 7 \\
\hline 0.06 & 0.60 & 0.30 & الترفيهي & 8 \\
\hline 1.70 & 18.48 & 9.24 & المقابر & 9 \\
\hline 23.75 & 100.00 & 50.01 & الجموع & \\
\hline
\end{tabular}

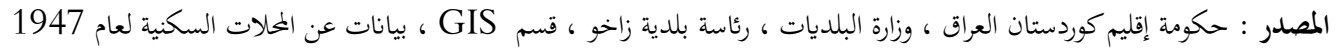

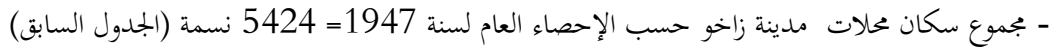
- مساحة البساتين = - النسبة المئوية لمساحة البساتين = 80.01 \%

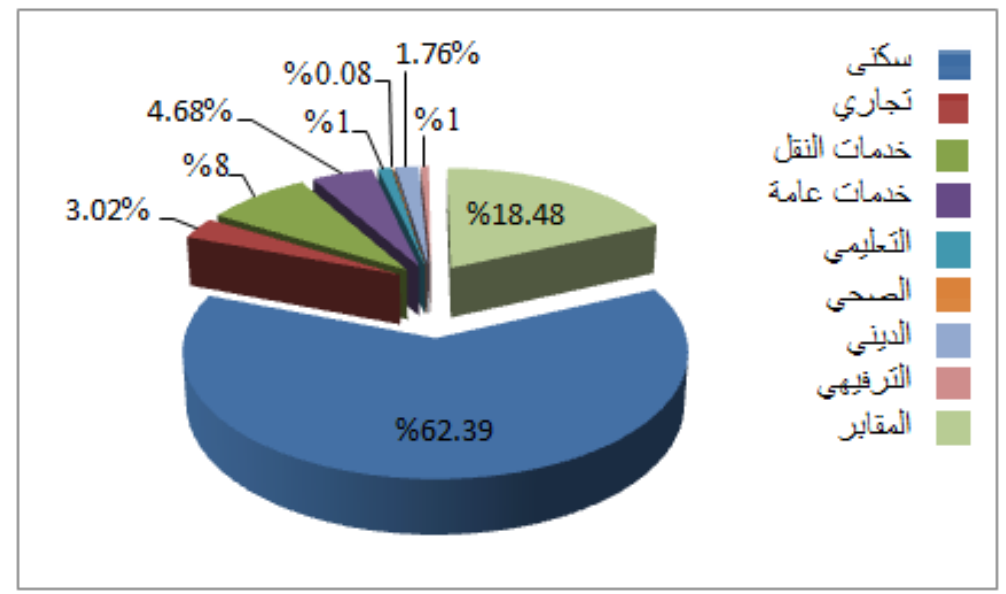

الشكل (3): إستعمالات الأرض الحضرية في مدينة زاخو غهاية المرحلة المورفولوجية الأولى عام 1947

المصدر : من عمل الباحثة بالإعتماد على الجدول رقم (2): إسعمات (2) 
مساحي 13.557هكتاربنسبة 22.56\% ، ومحلة الكندك

2. المرحلة المورفولوجية الثانية (1947- 1957) :

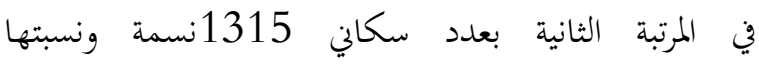

لقد حصلت تغيرات سكانية في فاية الأربعينات لخروج

16.65\% وبمساحة تقدر بـ 9.88 هكتار بنسبة

سكان اليهود من إحصاء 1957 وتهجيرهم إلى إسرائيل

16.44 من مساحة المدينة ، و و محلة الكيستة في المرتبة

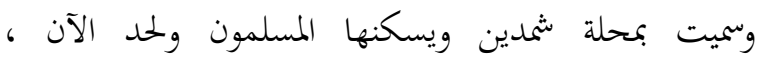
الثالثة وبلغت 1102 نسمة بنسبة 13.95\% على ملى مساحة

وأصبحت محلة الحسينية في المرتبة الأولى من حيث عدد قدرها 87.80\% بنسبة 13.11\% من مساحة المدينة .

السكان كما في الجدول رقم (3) حيث بلغت 1356 نسمة

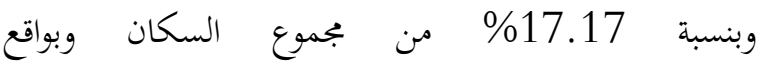

جدول (3): محلات مدينة زاخو غاية المرحلة المورفولوجية الثانية عام 1957

\begin{tabular}{|c|c|c|c|c|c|c|}
\hline الكثافة السكانية (نسمة/ & $(\%)$ & المساحة (هكتار) & $(\%)$ & عدد السكان (نسمة) & إسم الحلة & ت \\
\hline 222.51 & 7.84 & 4.710 & 13.27 & 1048 & شمدين (اليهود سابقاً) & 1 \\
\hline 238.94 & 4.51 & 2.712 & 8.20 & 648 & الروت & 2 \\
\hline 137.48 & 2.52 & 1.513 & 2.63 & 208 & القصابين & 3 \\
\hline 186.69 & 2.70 & 1.623 & 3.84 & 303 & السوق & 4 \\
\hline 189.92 & 2.15 & 1.290 & 3.10 & 245 & كوان & 5 \\
\hline 139.85 & 13.11 & 7.880 & 13.95 & 1102 & الكيستة & 6 \\
\hline 100.02 & 22.56 & 13.557 & 17.17 & 1356 & الحسينية & 7 \\
\hline 89.73 & 17.14 & 10.297 & 11.70 & 924 & النصارى & 8 \\
\hline 133.10 & 16.44 & 9.88 & 16.65 & 1315 & الكندك & 9 \\
\hline 113.01 & 11.03 & 6.628 & 9.48 & 749 & ركاوة*" & 10 \\
\hline 131.44 & 100 & 60.09 & 100 & 7898 & المجموع & \\
\hline
\end{tabular}

المصدر : الجمهورية العراقية ، وزارة الداخلية ، مديرية النفوس العامة ، المجموعة الإحصائية للتسجيل العام 1957 ، لوائي الموصل وأربيل ، مطبعة الإرشاد ، بغداد $115-113$ ص 113 *ركاوه - كانت قرية في بداية القرن التاسع عشر ثم أصبحت محلة من محلات زاخو في الخمسينات تقع شمال محلة اليهود (آزادي) خارج الجزرة الوسطية وعلى الضفة الثانية لنهر الخابور والواقع على الجرف الصخري المطل على النهر ، وسميت بـ ركافا لأها صامدة أمام طوفان النهر.

1954 (11) مو مشروع جديد للكهرباء في 1952، وتم فتح دائرة إخسار التبغ عام 1956 لبيع البذور وشراء التبغ بعد الحصاد، وفتح دائرة الإستهلاك لأخذ الرسوم على المبيعات . وكذلك تم فتح دائرة تسوية (عقارات) في بداية (13) الخمسينات، وإفتتاح السوق القريب من محلة الحسينية

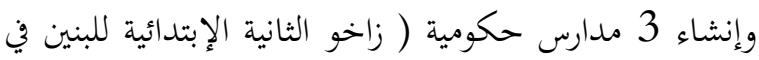
عام 1947، متوسطة زاخو المختلطة 1952 ومتوسطة زاخو للبنات 1957) (14) و إنشاء إبتدائية الأرمن الأهلية

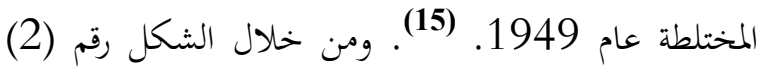
والجدول رقم (4) يتبين أن الإستعمال السكني شغلت

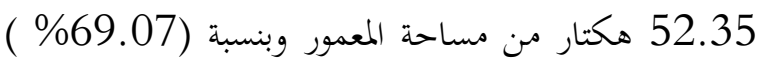
أما حصة الفرد فبلغت 66.283 م²، وزادت مساحة من مبنة
وظهرت لأول مرة أسماء محلات (القصابين ، الكوان ، السوق، الكيستة) في قوائم الإحصاءات السكانية بشكل مستقل ، وتبين أن محلة الكوان كانت من أصغر المحلات مساحة 1.290 هكتار بنسبة 2.15\% وتضم عدد سكانين 245 نسمة بنسبة 3.10\% . وتم أسر قرية ركاوه شمال الجزرة الوسطية وأصبحت من محلات زاخو والتي كانت تضم 749 نسمة على مساحة تقدر بـ 6.628 هكتار. أما

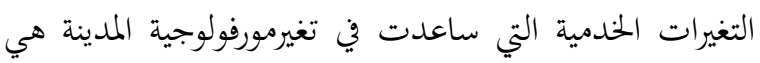
فتح شارع يوصل بين الجسرين (السعدون والفاروق) في الجزرة

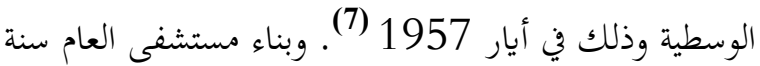

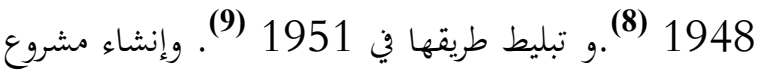
ماء عام 1952 (10) وفتح طريق زاخو. آميدي في عام فئل فئاء 
الخدمات التعليمية إلى 2,00 هكتار وبلغت حصة الفرد بنسبة ( 1.99\% ، 0.40\% ، 1.16\%) على التوالي . 2.532 م2 ، بينما بقيت مساحة ثلاث إستعمالات ثابتة أما مساحة البساتين فقد تقلصت وأصبحت 179.45 (التجاري"السوق" والترفيهي "نادي" ودور العبادة ) حيث ه هكتار وزادت على لمسابها علدد المحلات السكنية.

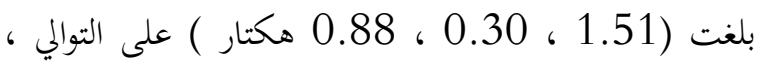
جدول (4): إستعمالات الأرض الحضرية وحصة الفرد منها في مدينة زاخو غاية المرحلة المورفولوجية الثانية عام 1957

\begin{tabular}{|c|c|c|c|c|}
\hline حصة الفرد من المساحة (م²) & $(\%)$ & المساحة (هكتار) & إستعمالات الأرض & ت \\
\hline 66.283 & 69.07 & 52.35 & السكني & 1 \\
\hline 1.912 & 1.99 & 1.51 & التجاري & 2 \\
\hline 5.368 & 5.59 & 4.24 & خدمات النقل & 3 \\
\hline 3.393 & 3.54 & 2.68 & خدمات عامة & 4 \\
\hline 2.532 & 2.64 & 2.00 & التعليمي & 5 \\
\hline 0.975 & 1.02 & 0.77 & الصحي & 6 \\
\hline 1.114 & 1.16 & 0.88 & الديني & 7 \\
\hline 0.380 & 0.40 & 0.30 & الترفيهي & 8 \\
\hline 12.497 & 13.02 & 9.87 & المقابر & 9 \\
\hline 1.507 & 1.57 & 1.19 & المعسكر & 10 \\
\hline 95.961 & 100 & 75.79 & المجموع & \\
\hline
\end{tabular}

المصدر : حكومة إقليم كوردستان العراق ، وزارة البلديات ، رئاسة بلدية زاخو ، قسم GIS ، بيانات عن المحلات السكنية لعام 1957 ، 1957 ، - مجموع سكان محلات مدينة زاخو حسب الإحصاء العام لسنة 1957=

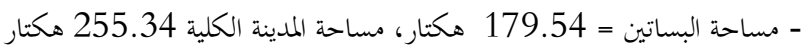
- النسبة المئوية لمساحة البساتين = 70.31 \%

زيادة وتيرة الهجرة (17) والطائرات العراقية قصفت القرى الكوردية الحدودية محا حدا بقوات البيشمركة في زاخو للقيام بتحرير المنطقة في ثورة 9 أيلول (18) ونتيجة لذلك حدثت الثينت عمليات هجرة وهجير وكانت معظم المناطق الكوردية خارج سيطرة الحكومة المركزية في بغداد لذلك فإن نتائج تعداد عام

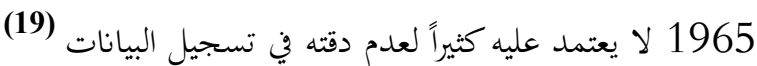

3. المرحلة المورفولوجية الثالثة (1957 - 1977) : شهدت المرحلة تغيرات سياسية وإقتصادية في عموم العراق إثر قيام ثورة 14 تموز عام 1958 بإطاحة النظام الملكي والدخول في العهد الجمهوري متبنياً العديد من المشاريع الإسكانية والعمرانية (16)، ولكن بين عامي 1962 - 1962 1974 شهدت المدن الكوردية أحداث سياسية تسببت في 


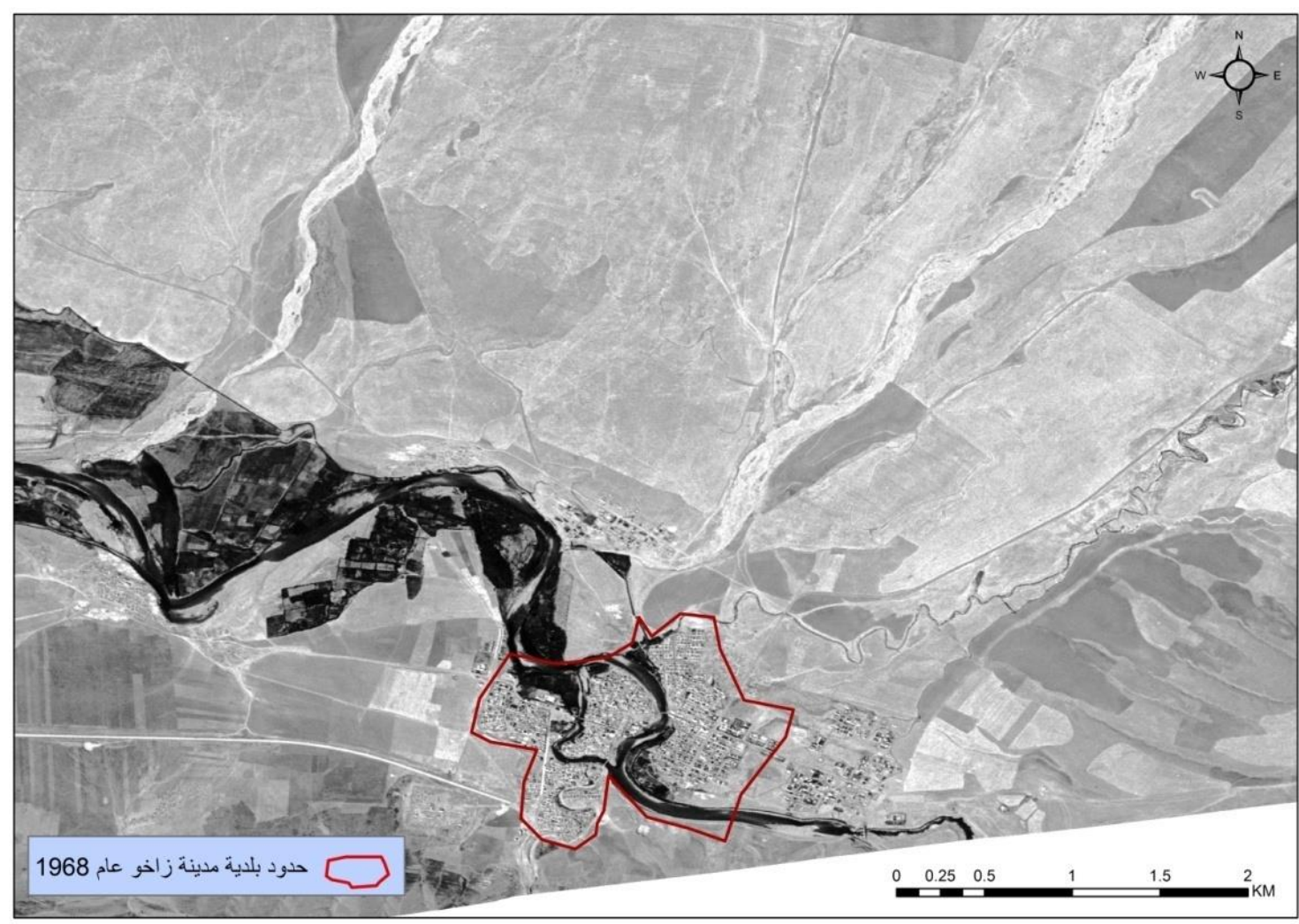

الشكل (4): صورة جوية لمدينة زاخو عام 1968

www.corona.com : المصدر

لقد زاد عدد سكان المدينة إلى 28526 نسمة في عام ، وبعدد سكاني 3869 نسمة وكذلك محلة نصارى بلغت 13.604 هكتار بنسبة 99.05\% وبعدد سكاد سكاني 2210 1977 (20) وذلك بسبب الإتفاقية المبرمة بين العراق وإيران

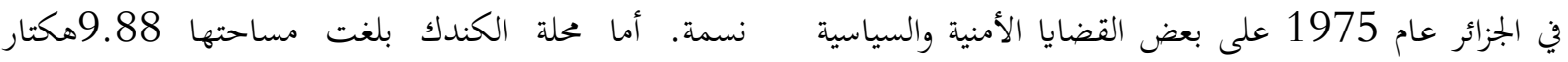
منها وقف دعم الحكومة الإيرانية للحركة والوطنية الكوردية في وبنسبة 6.57\% وبعدد سكانية سكاني 4170 نسمة، وتوسعت محلة ركاوة بشكل كبير وبلغت 12.17 هكتبنة 12.00 العراق نتجت عنه تدفق سكان القرى إلى المدن الكوردية (21) 8.09 \% من مساحة المدينة وبعدد سكاني 2284 نسمة. . وبذلك تغيرت مساحة بعض المحلات منها محلة الحسينية بحيث بلغت مساحتها 16.260 هكتار بنسبة 10.81

جدول (5): محلات مدينة زاخو فهاية المرحلة المورفولوجية الثالثة عام 1977

\begin{tabular}{|c|c|c|c|c|c|c|}
\hline (الكثافة السكانية & $(\%)$ & المساحة (هكتار) & $(\%)$ & عدد السكان & إسم الحلة & ت \\
\hline 266.30 & 5.07 & 7.623 & 7.11 & 2030 & الأحرار & 1 \\
\hline 260.44 & 2.88 & 4.335 & 3.96 & 1129 & السوق والروت & 2 \\
\hline 202.41 & 5.24 & 7.880 & 5.59 & 1595 & الكيستة & 3 \\
\hline 237.95 & 10.81 & 16.260 & 13.56 & 3869 & الحسينية & 4 \\
\hline 162.45 & 9.05 & 13.604 & 7.74 & 2210 & النصارى & 5 \\
\hline 422.06 & 6.57 & 9.88 & 14.61 & 4170 & الكندك & 6 \\
\hline 187.67 & 8.09 & 12.170 & 8.00 & 2284 & ركاوة & 7 \\
\hline 129.18 & 34.17 & 51.377 & 23.26 & 6637 & العباسية * & 8 \\
\hline
\end{tabular}




\begin{tabular}{|c|c|c|c|c|c|c|}
\hline 138.63 & 9.53 & 14.326 & 6.96 & 1986 & الشعبانية & 9 \\
\hline 203.60 & 8.58 & 12.898 & 9.20 & 2626 & سيمالكاو شكفتمارا & 10 \\
\hline 189.73 & 100 & 150.353 & 100 & 28526 & الجمموع & \\
\hline
\end{tabular}

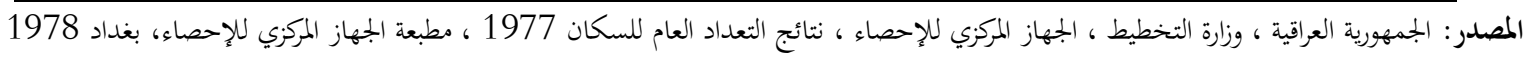
(*) العباسية كانت قرية جنوب شرق مينة زاخو مساحتها 0.220 هكتار، وأصبحت محلة سكنية في هذه المرحلة المورفولوجية .

ومستشفى الولادة في مركز المدينة، وفتح بيطرة زاخو، ومحطة كهرباء ونقليات للمسافرين وفتح شارع رئيسي بين محلتي الكيستة والحسينية، وفي عام 1975تم فتح الشارع الرئيسي الممتد من محلة الكندك شرقاً ماراً بمنطقة المقبرة القديمة وإقامة جسراً عسكرياً مؤقتاً على بعد أمتار من جسر دلال (29) . وتح إنشاء مستوصف (شمعون) الصحي وإنشاء كنيستين (مريم العذراء، الأرمن) (30) وفتح معمل البلوك مع سوق في مركز المدينة وإمتدت السوق فيما بعد إلى دورة بارزان الحالية ، هذا بالإضافة إلى مشاريع أخرى(31) كإنشاء مدرسة نموذجية وإبتدائية ذات12صف، وبناية التلقيح الإصطناعي التابعة للزراعة ودارين للمحجر الزراعي وبناية البلدية، سوق العصري،

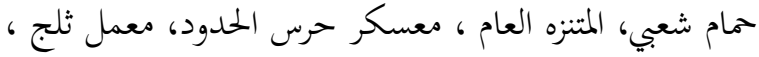
بناية الكمرك ، مخفر شرطة ، دائرة البريد، دار إستراحة ودائرة ودور للمهندسين. ومن الجدول رقم (6) تبين أن الإستعمال السكني سيطرت على حصة كبيرة من مساحة الحضر وإستحوذت على 132.89 هكتار من مساحة المعمور و

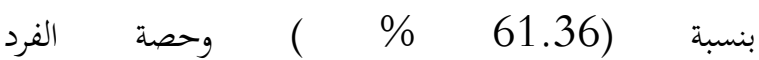
بلغت(46.586)م²وهي من الإستعمالات الغير المستقرة لمنافسة الوظيفة التجارية لها. وإحتلت المساحة التعليمية المرتبة الثانية بواقع (44.58)هكتار وبنسبة( 20.59\%)، وجاءت خدمات النقل في المرتبة الثالثة بواقع 16.35 هكتار وبنسبة (7.55\%) من مجموع مساحة المعمور، وحصة الفرد كانت 5.732م² ، وإنخفضت مساحة البساتين إلى 124.94

هكتار
لقد توسعت المدينة خارج الجزرة الوسطية في السبعينيات وإمتدت بإبتحاه الشرق والشمال و بدأت المدينة بأسر قرية العباسية شرقاً وتم توزيع الأراضي فيها على شهداء قادة ثورة أيلول (22) وبلغت مساحتها 51.377 هكتار وبنسبة \%34.71 من مساحة المعمور وبعدد سكاني 6637 نسمة وبنسبة 23.26\% وبذلك أصبحت من أكبر المحلات مساحةً وسكاناً .وظهرت محلة الشعبانية شنمال الجزرة الوسطية بمساحة 14.326 هكتار وبنسبة 9.53\% وبعدد سكاني 1986 نسمة بنسبة 6.96\% ، وذلك بعد 11 آذار 1975 شيد النازحون و المهاجرون مساكنهم وتوسعت عشوائياً بالأخص بعد إهيار الثورة الكوردية عام 1975 حيث تم إخلاء مناطق واسعة بصورة قسرية وإنشاء مناطق عسكرية لذا إنتشر السكن العشوائي في المدينة بضمنها

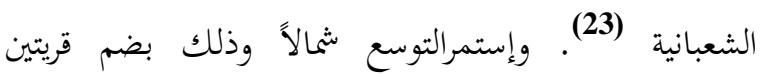
سيمالكا وشكفتمارا وتم دبجهما في الإحصاءات الرسمية وظهرت محلة سيمالكا *بعدد سكاني 2626 نسمة بنسبة \%.20\% وبمساحة 12.898 هكتار بنسبة 8.58\%. وبخصوص المشاريع في فهاية الستينات وفترة السبعينات تبين من خلال المقابلات الشخصية تم فتح مشروع الماء الثاني وإعدادية الزراعة وحقول حيوانية و زراعية (24) وكانت تملك 157 دونم من الأرض (25). وتم فتح 13 مدرسة حكومية (إبتدائية ومتوسطة وثانوية) (26) ، وبناء 3مساجد أخرى . الإحصاء والمكتبة العامة مع مركز شباب ، و دائرة الأنواء الجوية (28) .و إنشاء مستشفى الشعبانية عام 1975، 1975 
جدول (6): إستعمالات الأرض الحضرية وحصة الفرد منها في مدينة زاخو فاية المرحلة المورفولوجية الثالثة 1977

\begin{tabular}{|c|c|c|c|c|}
\hline من حصة المساحة (م²) & $\begin{array}{c}\text { النسبة المئوية } \\
\text { (\%) }\end{array}$ & (المساحة & إستعمالات الأرض & ت \\
\hline 46.586 & 61.36 & 132.89 & السكني & 1 \\
\hline 0.817 & 1.08 & 2.33 & التجاري & 2 \\
\hline 5.732 & 7.55 & 16.35 & خدمات النقل & 3 \\
\hline 2.128 & 2.80 & 6.07 & خدمات عامة & 4 \\
\hline 15.628 & 20.59 & 44.58 & التعليمي & 5 \\
\hline 0.670 & 0.88 & 1.91 & الصحي & 6 \\
\hline 0.557 & 0.73 & 1.59 & الديني & 7 \\
\hline 0.098 & 0.13 & 0.28 & الترفيهي & 8 \\
\hline 0.168 & 0.22 & 0.48 & الرياضي & 9 \\
\hline 3.116 & 4.11 & 8.89 & المقابر & 10 \\
\hline 0.417 & 0.55 & 1.19 & المعسكر & 11 \\
\hline 75.917 & 100.00 & 216.56 & & لجموع \\
\hline
\end{tabular}

المصدر : حكومة إقليم كوردستان العراق ، وزارة البلديات ، رئاسة بلدية زاخو ، قسم GIS ، بيانات عن المحلات السكنية لعام 1977 ، بلماع - مجموع السكان لمحلات مدينة زاخو حسب الإحصاء العام لسنة 1977=

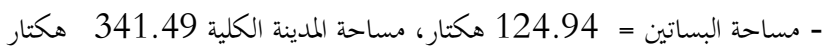
- النسبة المئوية لمساحة البساتين = 36.59 \%

إتسعت بشكل مذهل بحيث وصلت إلى 130.130 هكتار وبنسبة 25.11 \% وكذلك يلاحظ ظهور ستبك وصنة محلات جديدة في منتصف الثمانينات وهي محلة 7 نيسان (نوروز)

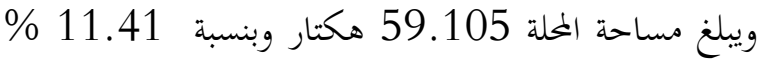
، وتم إنشاء محلة مجمع صلاح الدين غرب محلة الكندك ويبلغ

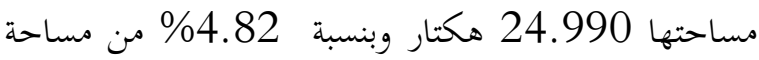
المعمور. وكانت أول بناء في محلة بيدار في الثمانينات منطقة تسمى بـ القصور الصفراء وهي محلة قزمية تقع غرب زاخو والبالغ مساحتها 1.850 هكتار في جنوب غرب قرية بيدار ولكنها نمت بشكل سريع وفي منتصف التسعينات بلغت مساحتها 30.050 هكتار .أما حي الجمعية (آشتي) شمال مجمع صلاح الدين والبالغ مساحتها 29.861 هكتار وبنسبة 5.76\% ظهرت بعد إتفاقية 11 آذار بين الحكومة المركزية والحركة الوطنية الكوردية وتم تشكيل جمعية لبناء المساكن في عام 1972. وإن أعلى الكثافات السكانية كانت في محلة الأحرار(اليهود) حيث بلغت 446.89 نسمة/هكتار، يليها محلة الكندك البالغ 368.28 نسمة/هكتار
4. المرحلة المورفولوجية الرابعة (1977 - 1987) : حافظت الجزرة الوسطية على مورفولوجيتها بسبب

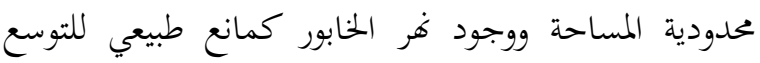
ولكن خارج الجزرة نمت بتسارع لتضم مساحات على حساب وتهود الأراضي الزراعية والقرى المجاورة فتوسعت في كافة الإتحاهات وأصبحت في منتصف الثمانينات 16 محلة وبمجموع سكاني 67236 نسمة حسب إحصاء 1987، كما في الجدول رقم (7) يشير إلى ظهور ستة محلات سكنية إلى الوجود (7)

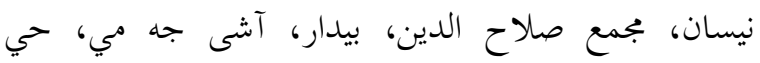

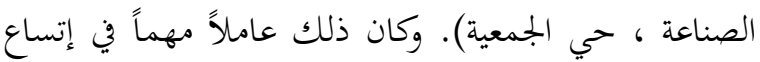
المدينة. بالنسبة لمحلة ركاوة توسعت بإبحاه الشرق والشمال

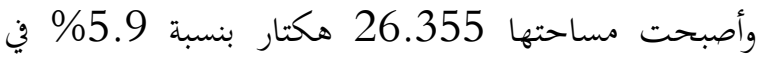
منتصف الثمانينيات، وبعدد سكاني 3129 نسمة بنسبة 4.65 \% وبكثافة سكانية 118.73 نسمة/هكتار، وكذلك محلة الحسينية إتسعت إلى 25.766 هكتار بنسبة 4.97 \% في الثمانينات. أما محلة العباسية فقد توسعت إنس بشكل كبير وتم تقسيمها وتحت إسم العباسية الأولى والثانية وقد تم دمج المساحتين تحت إسم محلة العباسية 118.8 هكتار لغرض الدراسة ، وأيضاً محلة سيمالكا - شكفتمارا 
جدول رقم (7): محلات مدينة زاخو فهاية المرحلة المورفولوجية الرابعة عام1987

\begin{tabular}{|c|c|c|c|c|c|c|}
\hline (لكثافة السكانية & $(\%)$ & المساحة * (هكتار) & $(\%)$ & عدد السكان & إسم الحلة & ت \\
\hline 446.89 & 1.20 & 6.223 & 4.13 & 2781 & الأحرار، قصابين & 1 \\
\hline 267.71 & 1.11 & 5.775 & 2.30 & 1546 & السوق ، روت ، كوان & 2 \\
\hline 277.28 & 1.52 & 7.880 & 3.25 & 2185 & الكيستة & 3 \\
\hline 205.70 & 4.97 & 25.766 & 7.87 & 5300 & الحسينية & 4 \\
\hline 222.51 & 2.63 & 13.604 & 4.50 & 3027 & النصارى & 5 \\
\hline 368.28 & 2.99 & 15.510 & 8.48 & 5712 & الكندك & 6 \\
\hline 118.73 & 5.09 & 26.355 & 4.65 & 3129 & ركاوة & 7 \\
\hline 76.52 & 22.93 & 118.819 & 13.50 & 9092 & العباسية (الأولى ، الثانية) & 8 \\
\hline 152.61 & 3.44 & 17.823 & 4.04 & 2720 & الشعبانية & 9 \\
\hline 27.64 & 25.11 & 130.130 & 5.34 & 3597 & سيمالكا و شكفتمارا & 10 \\
\hline 113.51 & 0.36 & 1.850 & 0.31 & 210 & بيدار (القصورالصفراء) & 11 \\
\hline 188.78 & 28.65 & 148.466 & 41.63 & 28027 & الجمعية ، آشى جه مى ، جمع صلاح الدين ، حي الصناعة ) & 12 \\
\hline 129.92 & 100 & 518.201 & 100 & 67326 & الجموع & \\
\hline
\end{tabular}

- لم نستطع الحصول على حجم سكان محلات (7 نيسان ، مجمع صلاح الدين ، حي الجمعية ، آشى جه مى ، حي الصناعة) لأهما محلات جلديدة لم يكن

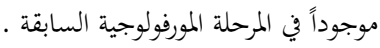

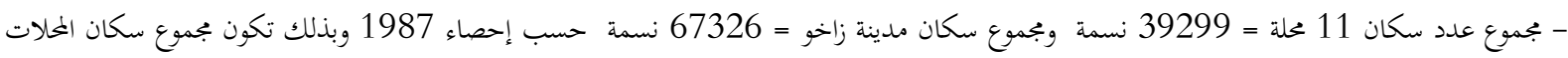
الغير المسجلة = 28027 نسمة . * يتم إستخراج عدد سكان كل محلة بضرب عدد سكاها في فاية المرحلة السابقة بـ (1.37) كمعدل نمو سنوي حسب الخبير الإحصائي المتقاعد صابر ياسين صالح ، محافظة دهوك .

ومن الخدمات والمشاريع التي لها دور في توسع المدينة ، من المعمور ، وزادت مساحة التعليمة والنقل مع الزيادة

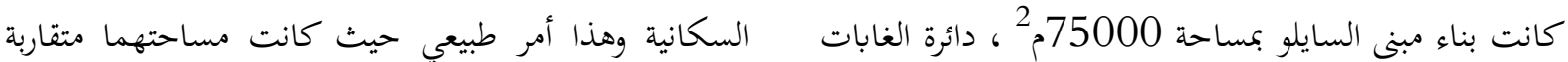

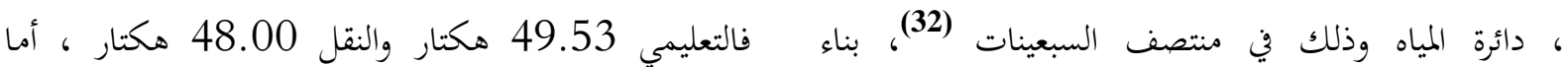

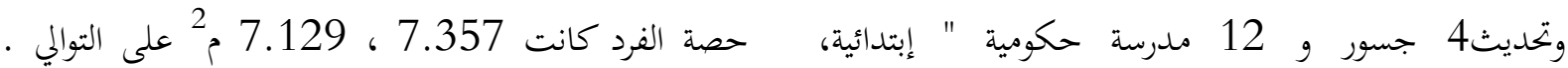

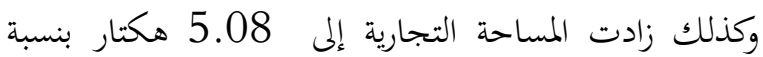
متوسطة، ثانوية" ونحديق وأصبح المجموع 28 مدرسة ، وتم فتح إعدادية صناعة عام (0.82\%) و والخدمات العامة توسعت إلى 21.45 هكتار

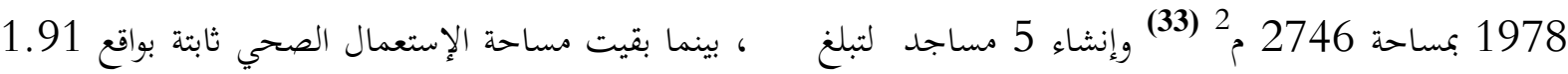

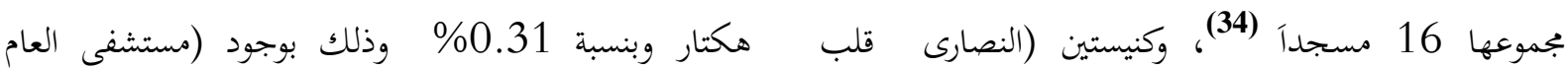

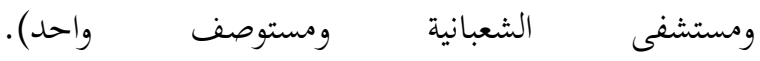

من خلال الجدول رقم (8) تبين هيمنة المساحة السكنية

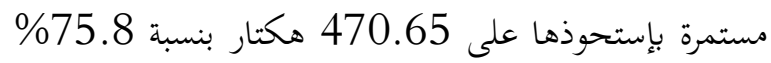


جدول (8 ): إستعمالات الأرض الحضرية وحصة الفرد منها في مدينة زاخو هاية المرحلة المورفولوجية الرابعة 1987

\begin{tabular}{|c|c|c|c|c|}
\hline 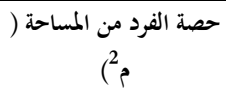 & $(\%)$ & المساحة (هكتار) & إستعمالات الأرض & ت \\
\hline 69.906 & 75.80 & 470.65 & السكني & 1 \\
\hline 0.755 & 0.82 & 5.08 & التجاري & 2 \\
\hline 7.129 & 7.73 & 48.00 & خدمات نقل & 3 \\
\hline 3.186 & 3.45 & 21.45 & الخدمات عامة & 4 \\
\hline 7.357 & 7.98 & 49.53 & التعليمي & 5 \\
\hline 0.284 & 0.31 & 1.91 & الصحي & 6 \\
\hline 0.282 & 0.31 & 1.90 & الديني & 7 \\
\hline 0.189 & 0.20 & 1.27 & الترفيهي & 8 \\
\hline 0.168 & 0.18 & 1.13 & الرياضي & 9 \\
\hline 1.384 & 1.50 & 9.32 & المقابر & 10 \\
\hline 1.579 & 1.71 & 10.63 & المعسكر & 11 \\
\hline 92.218 & 100 & 620.86 & الجمموع & \\
\hline
\end{tabular}

المصدر : حكومة إقليم كوردستان العراق ، وزارة البلديات ، رئاسة بلدية زاخو ، قسم GIS ، بيانات عن المحلات السكنية لعام 1987. - مجموع سكان محلات مدينة زاخو حسب إحصاء سنة 1987=

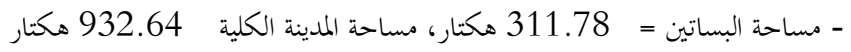

- النسبة المئوية لمساحة البساتين = 33.43 \%

5. المرحلة المورفولوجية الخامسة (1987-2009 )

ومحلة واحدة منشقة من العباسية وأخرى منشقة من سيمالكا ) . والمحلات الجديدة التي ظهرت إلى الوجود هي محلة مهاباد

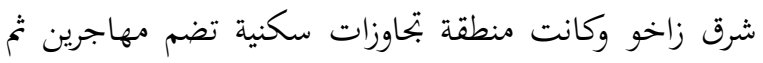

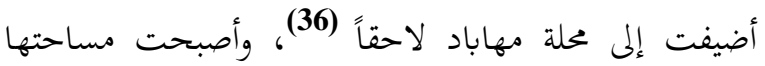

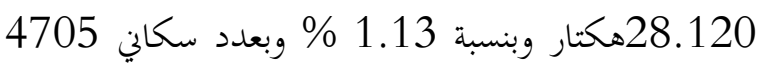
نسمة وبكثافة سكانية 167.32 نسمة/هكتار. بالنسبة لمحلة هيزل شمال شرق زاخو والمسمى عامياً بـ (الفرقة) ، وكانت بالأصل منطقة تجاوزات سكنها العائدين من إيران وتركيا،

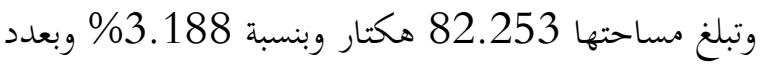

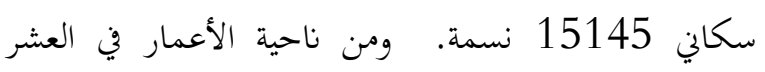
سنوات الأخيرة من هذه المرحلة وبالتحديد (2006، 2007، 2008، 2009) بلغت عدد إجازات الهدم والبناء المرخصة (603 ، 771 ، 867 ، 1085 ) 1067 )على التوالي وهذا يعني خلال أربع سنوات الأخيرة تم ترخيص (3326) إجازة هدم وبناء (37)، ومن جهة أخرى توسعت المدينة على لئل

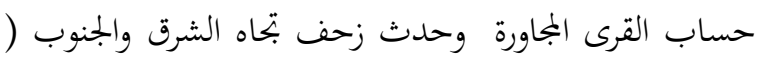

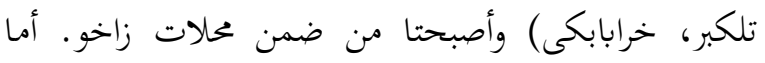

وفي هذه المرحلة الطويلة (22سنة) توسعت المدينة في كل الإتجاهات ، كانت عدد القطع السكنية المرقمة 6500 قطعة لرة

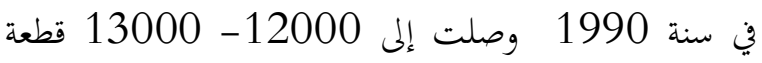
خلال الفترة 1999 - 2000 ، و وهذا يعني أن الزيادة في

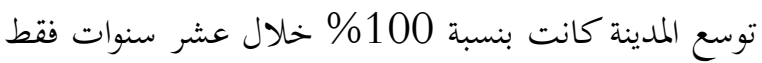
(35) فبعد أن كانت المدينة تضم 16 محلة أصبحت تضم34 محلة كما في الجدول رقم ( 9) ، أي زادت 18

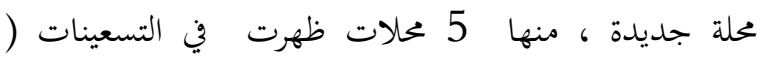
مهاباد ، هيزل ، شهيدان ، حي الصناعة الجديد ، آشتي) و و منهات

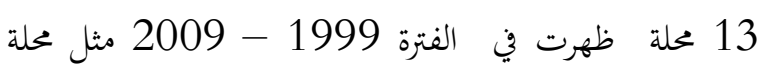
(المجمع التجاري ، بيشمه ركة ، جهه كه رخوين ، أياز، أردوان

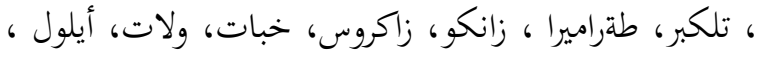

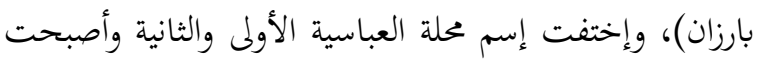

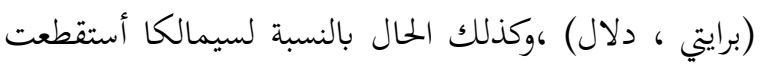
جزء كبير من غربها وسميت بالمهمدية نسبة إلى إسم القرية التي كانت بالأصل في نفس المكان عندما زحفت سيمالكا عليها، وبذلك أصبح مجموع المحلات 36 محلة (18 بحلة جديدة 
تجاوزات) ومكتضة بالسكان تقع في الوادي بين محلة نوروز

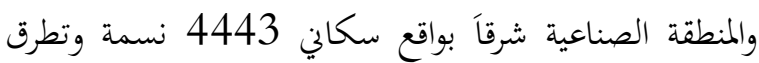
إليها الدراسة لأها جزء كبير من المساحة المبنية بواقع 44.6895 هكتار • بالرغم من أن جزء صغير من محلة بيدار كانت قد فـ شغلت مساحة صغيرة (القصور الصفراء) ، إلاّ أن الظهور الحقيقي لها كانت بداية التسعينيات عند توزيع قطع الأراضي في عام 1997 وثاني توزيع عام 1999وأصبحت مساحتها 165.225 هكتار بنسبة 66.66\% بعد أن ضمت قرية عالية بيدار إليها (41) ، ويبلغ عدد سكاهار بنسبة 9847 نسمة ونسبتها 5.54 ، وتوسعت المحلة غرباً بعد توزيع الأراضي السكنية على كوادر الحزب الديمقراطي الكوردستاني وعلى عوائل شهداء ومعوقي الثورة وسميت الجهة الشرقية (بيدار الشهداء)

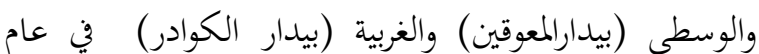

(42) 2004

والجدول (9) يبين حدوث إنقسام في محلة العباسية إلى

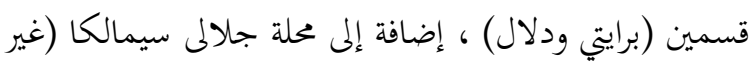

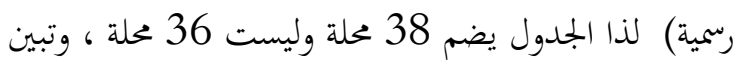
أيضاً أن المحلات السكنية القريبة من الأسواق التجارية تتقلص نهم حجمها السكاني من فترة لأخرى وذلك بزحف الإستعمال التجاري والنقل مثل محلات (الكيستة، بدرخان، آزادي) فمحلة الكيستة في مركز المدينة إنخفضت عدد سكاها إلى

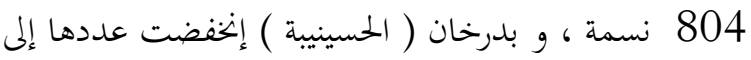
2548 نسمة في هاية 2009 ، ويف الجزرة الوسطية عانت محلة آزادي الأمرين وذلك بغزو الأسواق وزحف الطرق عليها نظرأ لوقوعهما على الشارع الرئيسي الموصل بين الجسرين (نرون فاروق - سعدون ) وفي منتصف الخمسينات تم هدم العديد

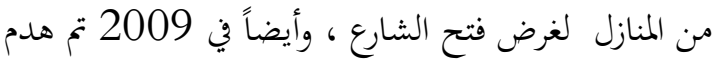

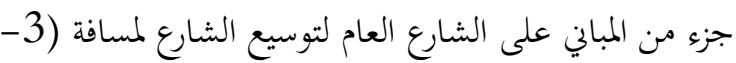
5) م حسب حاجة الشارع (43) لتواكب الزيادة السكانية والسيارات وتخفيف من حدة الإزدحام.
المحلات الجديدة التي ظهرت بين 1999 - 2009 فكانت

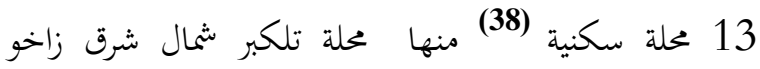
كانت قرية حتى بداية 2004 بمساحة 6.850 هكتار ثمخ

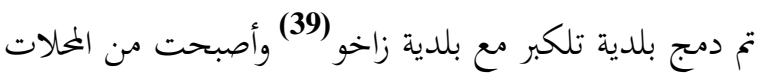

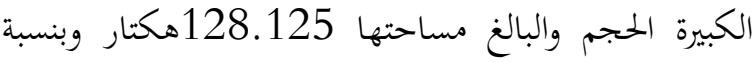
5.16 \% وبعدد سكاني 13040 نسمة ، ومحلة أياز في

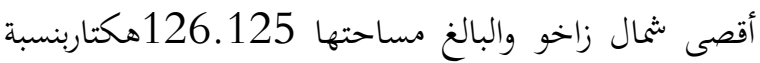
5.08\% وبعدد سكاني 870 نسمة. وظهرت محلة بيشمه واخد

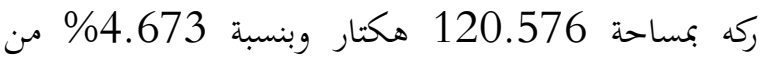
المعمور وبعدد سكاني 8218 نسمة وبكثافة سكانة سكانية 68.16 نسمة/ هكتار ، فقد تم توزيع 70\% من قطع

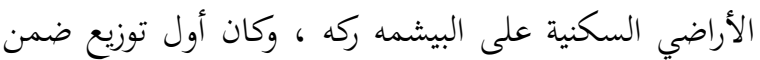

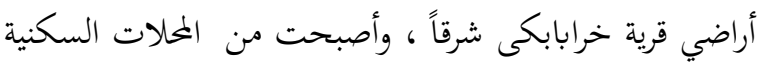

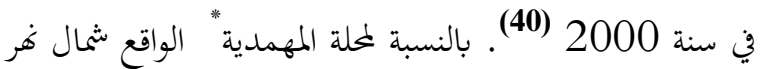
الخابور مباشرة ، تبلغ مساحتها 39.473 هكتار بنسبة

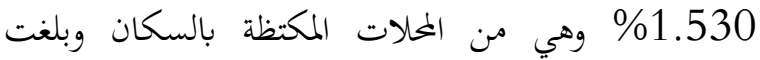
10742 نسمة بنسبة (66.05\%) وبكثافة سكانية

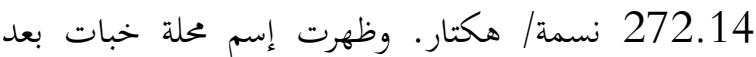
شطر القسم الجنوبي من محلة الشعبانية وتفصل بينهما شارع خبات - شعبانية والبالغ مساحتها 12.702 بنسبة 0.51 بندئ

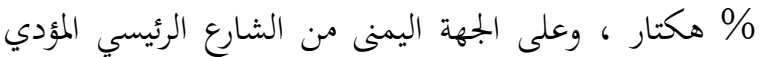
إلى دهوك برزت محلة زانكو البالغ مساحتها 130.108 هكتار وبنسبة 5.24 \% وبواقع سكاني 480 نسمة بنسبة

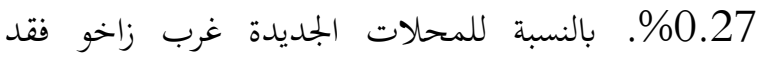
ظهرت محلة المجمع التجاري على الطريق الدولي (إبراهيم

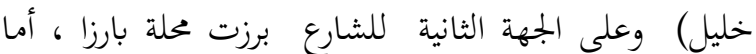
شمالاً فظهرت محلة جه كه رخوين وهي من المحلات الكبيرة

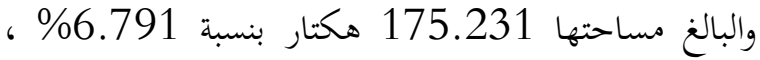
وظهرت محلة أيلول شمال غر الخابور، مساحتها 41.103 هكتار وبعدد سكاني 5496 نسمة وكذلك محلة ولات (منطقة الأكاديمية العسكرية) البالغ مساحتها 28.580 هكتار. هذا بالإضافة إلى محلة جلالى سيمالكا الغير رسمية ( 


\section{جدول (9): سكان ومساحة محلات مدينة زاخو في فاية المرحلة المورفولوجية الخامسة عام 2009}

\begin{tabular}{|c|c|c|c|c|c|c|}
\hline (الكثافة السكانية & $(\%)$ & $\begin{array}{l}\text { (المساحتار) } \\
\text { (هكتار) }\end{array}$ & $(\%)$ & عدد السكان & إسم الحلة & ت \\
\hline 282.66 & 0.25 & 6.223 & 0.99 & 1759 & آزادي والقصابين (الأحرار سابقا) & 1 \\
\hline 158.08 & 0.22 & 5.339 & 0.48 & 844 & خابير(السوق ، الروت ، كوان) & 2 \\
\hline 102.03 & 0.32 & 7.880 & 0.45 & 804 & الكيستة & 3 \\
\hline 98.89 & 1.04 & 25.766 & 1.43 & 2548 & بدرخان (الحسينية) & 4 \\
\hline 121.14 & 0.55 & 13.604 & 0.93 & 1648 & النصارى & 5 \\
\hline 189.17 & 0.62 & 15.510 & 1.65 & 2934 & الكندك & 6 \\
\hline 103.02 & 1.06 & 26.355 & 1.53 & 2715 & ركاوة & 7 \\
\hline 211.88 & 1.94 & 48.036 & 5.73 & 10178 & برايه تي (العباسية الأولى) & 8 \\
\hline 156.70 & 0.75 & 18.590 & 1.64 & 2913 & دلال (العباسية الثانية) & 9 \\
\hline 180.78 & 0.72 & 17.823 & 1.81 & 3222 & الشعبانية & 10 \\
\hline 191.87 & 1.70 & 42.284 & 4.57 & 8113 & سيمالكا & 11 \\
\hline 85.10 & 1.83 & 45.325 & 2.17 & 3857 & شكفتمارا & 12 \\
\hline 199.08 & 1.01 & 24.990 & 2.80 & 4975 & بجمع صلاح الدين & 13 \\
\hline 105.65 & 1.56 & 38.722 & 2.30 & 4091 & آشى جه مى (حي الشهداء ) & 14 \\
\hline 276.20 & 2.38 & 59.105 & 9.19 & 16325 & نوروز (7 نيسان ) & 15 \\
\hline 75.05 & 1.15 & 28.500 & 1.20 & 2139 & كاوه (حي الصناعة - بارك) & 16 \\
\hline 4.25 & 4.53 & 112.503 & 0.27 & 478 & حي الصناعة الجديدة (سايلو) & 17 \\
\hline 59.60 & 6.66 & 165.225 & 5.54 & 9847 & بيدار & 18 \\
\hline 116.12 & 3.67 & 91.120 & 5.96 & 10581 & زاكروس & 19 \\
\hline 167.32 & 1.13 & 28.120 & 2.65 & 4705 & مهاباد & 20 \\
\hline 27.97 & 7.06 & 175.231 & 2.76 & 4902 & جة كرخوين & 21 \\
\hline 184.13 & 3.31 & 82.253 & 8.53 & 15145 & هيزل & 22 \\
\hline 59.06 & 3.63 & 90.081 & 3.00 & 5320 & الشهيدان & 23 \\
\hline 272.14 & 1.59 & 39.473 & 6.05 & 10742 & مهمدية & 24 \\
\hline 68.16 & 4.86 & 120.576 & 4.63 & 8218 & البيشمرطة & 25 \\
\hline 128.80 & 0.51 & 12.702 & 0.92 & 1636 & خبات & 26 \\
\hline 0.27 & 3.43 & 85.125 & 0.01 & 23 & أردوان & 27 \\
\hline 6.90 & 5.08 & 126.125 & 0.49 & 870 & أياز & 28 \\
\hline 4.07 & 2.91 & 72.250 & 0.17 & 294 & طةراميرا & 29 \\
\hline 101.78 & 5.16 & 128.125 & 7.34 & 13040 & ت تلكبر & 30 \\
\hline 3.69 & 5.24 & 130.108 & 0.27 & 480 & زانكو & 31 \\
\hline 135.66 & 1.62 & 40.277 & 3.08 & 5464 & آشتى (حي الجمعية) & 32 \\
\hline 41.37 & 4.65 & 115.500 & 2.69 & 4778 & بارزان & 33 \\
\hline 133.71 & 1.66 & 41.103 & 3.09 & 5496 & أيلول & 34 \\
\hline 4.58 & 9.68 & 240.152 & 0.62 & 1100 & كولان & 35 \\
\hline 34.50 & 1.15 & 28.580 & 0.56 & 986 & ولات & 36 \\
\hline 0.15 & 3.56 & 88.311 & 0.01 & 13 & البمع التجاري & 37 \\
\hline 99.42 & 1.80 & 44.6895 & 2.50 & 4443 & جلالى سيمالكا (بتحاوزات) & 38 \\
\hline 71.57 & 100.00 & 2481.68 & 100 & 177626 & & المجموع \\
\hline
\end{tabular}

* إنقسمت محلة العباسية ( الأولى والثانية ) إلى قسمين القسم الشمالي سميت برايتي والقسم الجنوبي سميت دلال 
خمسة مراكز صحية في المحلات السكنية وبمساحات مختلفة

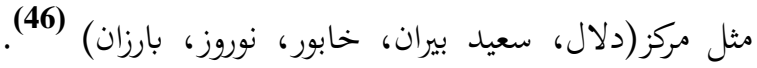
ومن خلال الجدول(10)تبين إستمرار إرتفاع الإستعمال

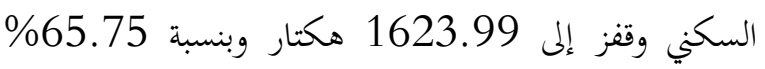

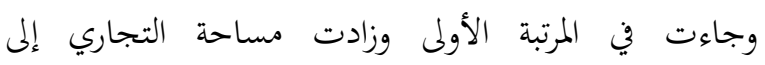
237,25 هكتار بنسبة 9.61\% وجاءت في فئس المرتبة الثانية

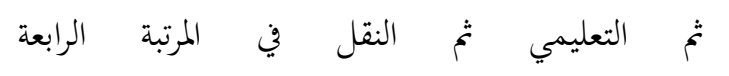

مشروع وذلك في الفترة 2000 - 2006، أما في سنة

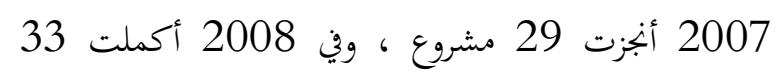
مشروع ومنها (44) فتح وتبليط الشوارع الداخلية وإنشاء جسور معلقة وحدائق في المحلات السكنية وإنشاء شوارع

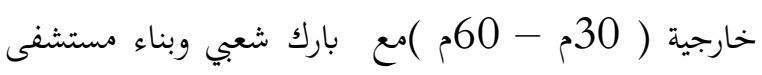
العام وقسم الطوارئ مع مركزين صحيين ، (45) و و إنشاء

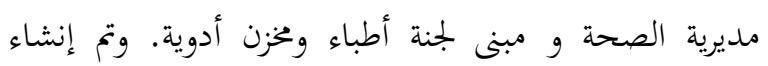
جدول (10): إستعمالات الأرض الحضرية وحصة الفرد منها في مدينة زاخو فاية المرحلة المورفولوجية الخامسة 1987- 2009

\begin{tabular}{|c|c|c|c|c|}
\hline حصة الفرد من المساحة ( م²) & $(\%)$ & المساحة (هكتار) & إستعمالات الأرض & 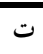 \\
\hline 91.427 & 65.75 & 1623.99 & السكني & 1 \\
\hline 13.357 & 9.61 & 237.25 & التجاري & 2 \\
\hline 5.971 & 4.29 & 106.06 & الصناعي & 3 \\
\hline 8.238 & 5.92 & 146.33 & خدمات النقل & 4 \\
\hline 3.907 & 2.81 & 69.40 & خدمات عامة & 5 \\
\hline 9.979 & 7.18 & 177.25 & التعليمي & 6 \\
\hline 0.329 & 0.24 & 5.84 & الصحي & 7 \\
\hline 0.431 & 0.31 & 7.65 & الديني & 8 \\
\hline 1.900 & 1.37 & 33.75 & الترفيهي & 9 \\
\hline 0.551 & 0.40 & 9.79 & الرياضي & 10 \\
\hline 0.740 & 0.53 & 13.14 & المقابر & 11 \\
\hline 2.217 & 1.59 & 39.38 & المعسكر & 12 \\
\hline 139.047 & 100.00 & 2469.83 & البمونع & \\
\hline
\end{tabular}

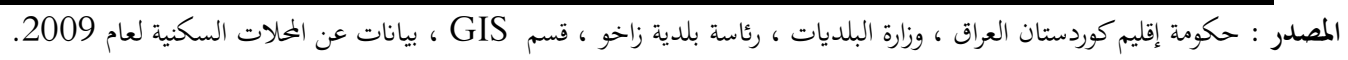
- مجموع سكان محلات مدينة زاخو حسب الإحصاء سنة 2009=

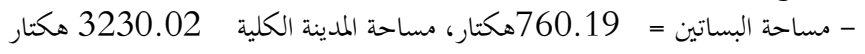
- النسبة المئوية لمساحة البساتين = 23.54 \%

قسم إجازات البناء - بلدية زاخو إتضح أغها كانت فترة نمو

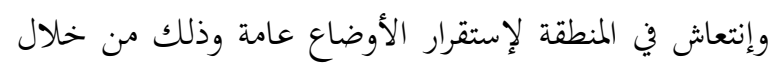
عدد الإجازات المرخصة في السنوات (2009 - 2010 - 2010 ) 2011 1463،1085، 1522، 1816، 1363) على التوالي وبجموع التراخيص خلال 5 سنوات بلغت 7279 ترخيصاً،

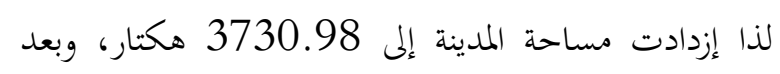

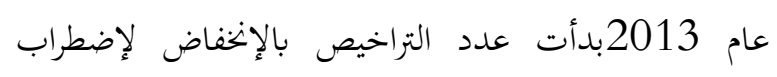

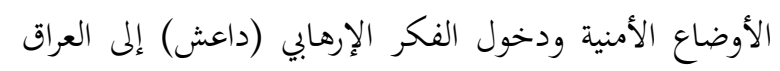

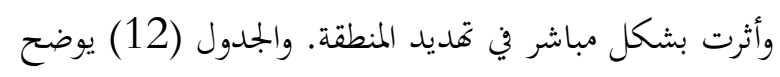

\section{6.} 2017) تمتاز بقصر فترها (8 سنوات) وظهرت 9 محلات

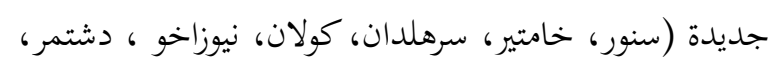

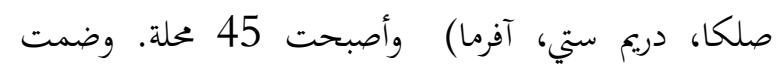

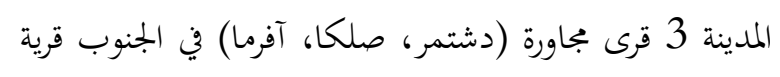

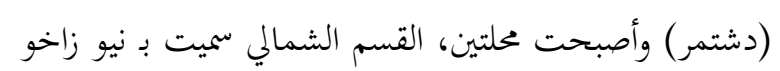

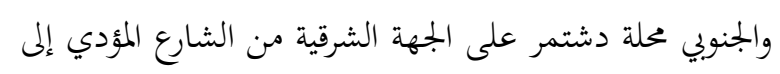

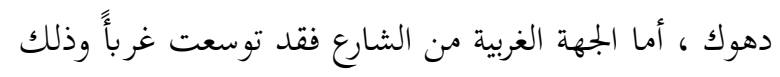

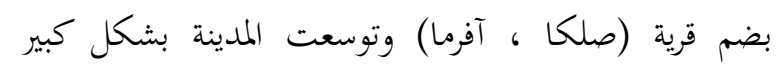
بالأخص في الفترة (2009 - 2013) حسب ماوردنا من 
أن أكبر المحلات مساحة هي محلة كولان 462.267 كانت من نصيب أقدم المحلات (كيستة، آزادي "يهود" هكتار، وتليها محلة دشتمرى 197.902 هكتار ثم محلة $7.892 \quad 7.015$ 7 7. زانكو 186.254 هكتار، وإن أصغر المحلات السكنية

جدول (11): سكان ومساحة محلات مدينة زاخو في خاية المرحلة المورفولوجية السادسة عام2017

\begin{tabular}{|c|c|c|c|c|c|c|}
\hline الكثافة السكانية (نسمة/ هكتار) & $(\%)$ & المساحة (هكتار) & $(\%)$ & عدد السكان (نسمة) & إسم المحلة & ت \\
\hline 329.63 & 0.17 & 7.02 & 0.99 & 2314 & ئازادي (الأحرا ر والقصابين) & 1 \\
\hline 173.34 & 0.15 & 6.19 & 0.46 & 1073 & خابير (كوان ، السوق والروت) & 2 \\
\hline 139.04 & 0.19 & 7.89 & 0.47 & 1097 & الكيستة & 3 \\
\hline 224.96 & 0.34 & 14.22 & 1.36 & 3199 & بدرخان (الحسينية سابقا) & 4 \\
\hline 110.05 & 0.40 & 16.61 & 0.78 & 1828 & النصارى & 5 \\
\hline 154.18 & 0.55 & 22.98 & 1.51 & 3543 & الكندك & 6 \\
\hline 174.96 & 0.47 & 19.57 & 1.46 & 3424 & ركاوة & 7 \\
\hline 263.39 & 1.25 & 51.82 & 5.82 & 13649 & 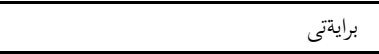 & 8 \\
\hline 178.80 & 0.51 & 21.27 & 1.62 & 3803 & إه لال & 9 \\
\hline 194.74 & 0.51 & 21.29 & 1.77 & 4146 & الشعبانية & 10 \\
\hline 193.67 & 0.28 & 11.69 & 0.96 & 2264 & خبات & 11 \\
\hline 230.00 & 1.04 & 43.43 & 4.26 & 9989 & سيمالكا & 12 \\
\hline 102.41 & 1.19 & 49.31 & 2.15 & 5050 & 1 شكتمارا & 13 \\
\hline 306.51 & 1.47 & 61.29 & 8.01 & 18786 & نوروز (7 نيسان سابقًاً ) & 14 \\
\hline 221.46 & 0.67 & 27.73 & 2.62 & 6141 & مجمع صلاح الدين & 15 \\
\hline 178.55 & 0.97 & 40.33 & 3.07 & 7201 & آشتي (حي الجمعية سابقاً) & 16 \\
\hline 97.34 & 1.30 & 54.05 & 2.24 & 5261 & آشى جه مى & 17 \\
\hline 4.05 & 3.73 & 155.18 & 0.27 & 628 & ثيشةزازى (الصناعة الجديدة ، سايلو سابقاً) & 18 \\
\hline 137.08 & 2.42 & 100.66 & 5.88 & 13798 & 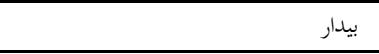 & 19 \\
\hline 287.20 & 1.08 & 44.91 & 5.50 & 12898 & 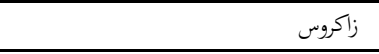 & 20 \\
\hline 217.83 & 0.64 & 26.70 & 2.48 & 5816 & 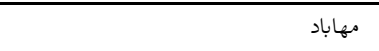 & 21 \\
\hline 233.49 & 1.94 & 80.84 & 8.04 & 18875 & هيزل & 22 \\
\hline 73.33 & 2.48 & 103.22 & 3.23 & 7569 & الشهيدان & 23 \\
\hline 0.27 & 2.12 & 88.31 & 0.01 & 24 & البممع التجاري & 24 \\
\hline 70.10 & 3.48 & 144.80 & 4.33 & 10150 & البيشمرطة & 25 \\
\hline 55.39 & 4.26 & 177.18 & 4.18 & 9814 & جة كرخوين & 26 \\
\hline 0.89 & 3.56 & 148.11 & 0.06 & 132 & أردوان & 27 \\
\hline 6.64 & 4.22 & 175.31 & 0.50 & 1164 & أياز & 28 \\
\hline 16.08 & 2.56 & 106.50 & 0.73 & 1712 & طةراميرا & 29 \\
\hline 102.39 & 3.92 & 162.93 & 7.11 & 16682 & تلكبر & 30 \\
\hline 43.78 & 3.56 & 148.18 & 2.77 & 6488 & بارزان & 31 \\
\hline 16.60 & 1.89 & 78.68 & 0.56 & 1306 & وه لات & 32 \\
\hline 343.32 & 0.96 & 39.98 & 5.85 & 13726 & مهمدية & 33 \\
\hline 10.81 & 3.29 & 136.95 & 0.63 & 1480 & سرهلدان & 34 \\
\hline 4.23 & 11.12 & 462.27 & 0.83 & 1954 & كولان & 35 \\
\hline 118.79 & 1.43 & 59.49 & 3.01 & 7067 & أيلول & 36 \\
\hline 106.35 & 0.77 & 31.83 & 1.44 & 3385 & كاوة (حي الصناعة - بارك سابقا) & 37 \\
\hline 3.86 & 2.67 & 110.88 & 0.18 & 428 & نيو زاخو & 38 \\
\hline 123.34 & 1.07 & 44.69 & 2.35 & 5512 & جلالى سى مالكا & 39 \\
\hline 0.60 & 3.55 & 147.49 & 0.04 & 89 & زانكو & 40 \\
\hline- & 4.41 & 183.23 & - & - & مريم ستي & 41 \\
\hline
\end{tabular}


مجلة جامعة دهوك، المجلد: 23، العدد: 1 (العلوم الانسانية والاجتماعية)، ص 161-185، 2020

\begin{tabular}{|c|c|c|c|c|c|c|}
\hline 2.23 & 4.76 & 197.90 & 0.19 & 441 & ده شرى & 42 \\
\hline 0.00 & 4.48 & 186.25 & 0.00 & 0 & صه لكا & 43 \\
\hline 1.50 & 3.85 & 160.27 & 0.10 & 240 & سنور & 44 \\
\hline 4.93 & 2.40 & 99.82 & 0.21 & 492 & خامتير & 45 \\
\hline- & 1.92 & 79.71 & - & - & آفرما & 46 \\
\hline 56.42 & 100 & 4156.96 & 100 & 234638 & الجموع & \\
\hline
\end{tabular}

المصدر : حكومة أقليم كردستان العراق ، وزارة التخطيط ، الميئة العليا للإحصاء ، مديرية إحصاء دهوك ،قسم السكان ، بيانات محلات زاخو ، 2017 ( بيانات

غير منشورة)

وةلات إستقطعت جزء من غرب سيمالكا لصالحها وبلغت

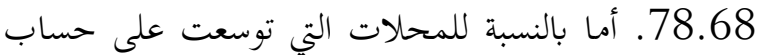

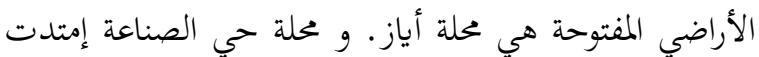

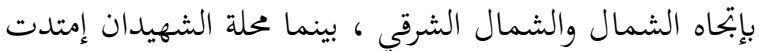

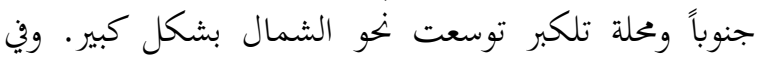

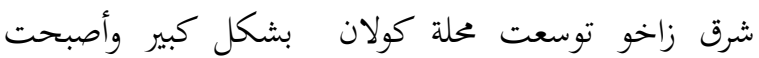

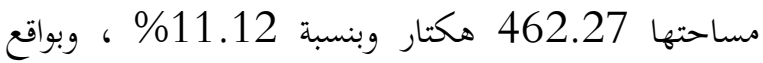

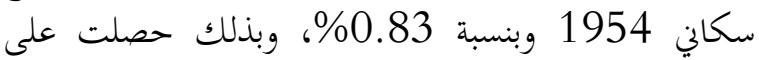

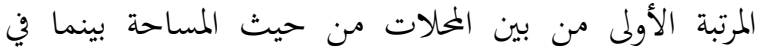

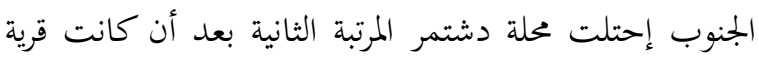

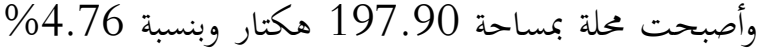

في بداية هذه المرحلة ظهرت إلى الوجود محلات (سنور،

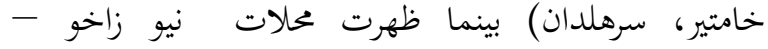

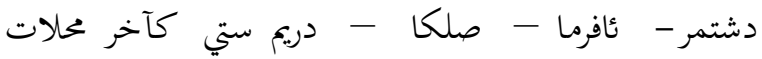
جديدة في نهاية المرحلة ، ونيو زاخو كانت خطة إستئمارية

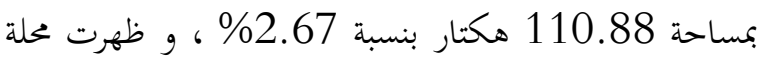

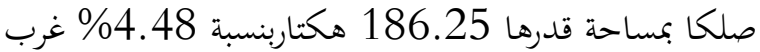

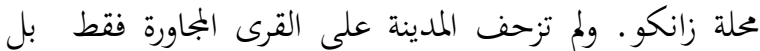
زحفت بعض المحلات على محلات أخرى وتم المعل تغير أسماءها

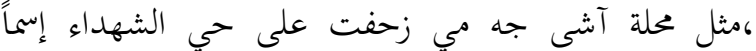

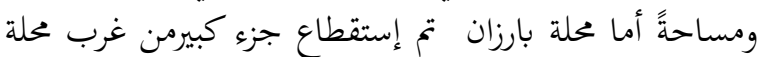

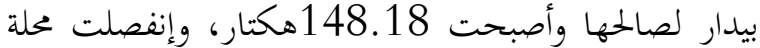

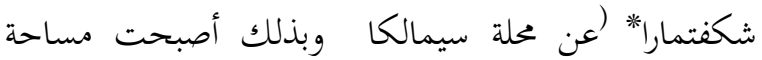
سيمالكا 43.43 هكتار بنسبة 1.04\% ، بالنسبة فلملة

جدول (12): إستعمالات الأرض الحضرية وحصة الفرد في مدينة زاخو فهاية المرحلة المورفولوجية السادسة عام 2017

\begin{tabular}{|c|c|c|c|c|}
\hline 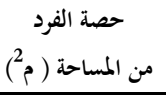 & $(\%)$ & 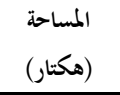 & إستعمالات الأرض & ت \\
\hline 112.35 & 70.66 & 2636.24 & السكني & 1 \\
\hline 13.18 & 8.29 & 309.16 & التجاري & 2 \\
\hline 4.66 & 2.93 & 109.29 & الصناعي & 3 \\
\hline 10.24 & 6.44 & 240.36 & خدمات النقل & 4 \\
\hline 3.32 & 2.09 & 77.95 & خدمات عامة & 5 \\
\hline 8.07 & 5.07 & 189.32 & التعليمي & 6 \\
\hline 0.45 & 0.28 & 10.52 & الصحي & 7 \\
\hline 0.51 & 0.32 & 12.04 & الديني & 8 \\
\hline 2.63 & 1.66 & 61.79 & الترفيهي & 9 \\
\hline 1.11 & 0.70 & 26.02 & الرياضي & 10 \\
\hline 0.81 & 0.51 & 18.91 & المقابر & 11 \\
\hline 1.68 & 1.06 & 39.38 & المعسكر & 12 \\
\hline 159.01 & 100.00 & 3730.98 & & المجموع \\
\hline
\end{tabular}

- مجموع سكان محلات مدينة زاخو = 234638 نسمة حسب مديرية إحصاء دهوك ، شعبة GIS وشعبة السكان( بيانات غير منشورة).

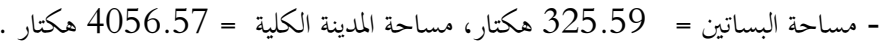

- النسبة المئوية لمساحة البساتين = 8.03 


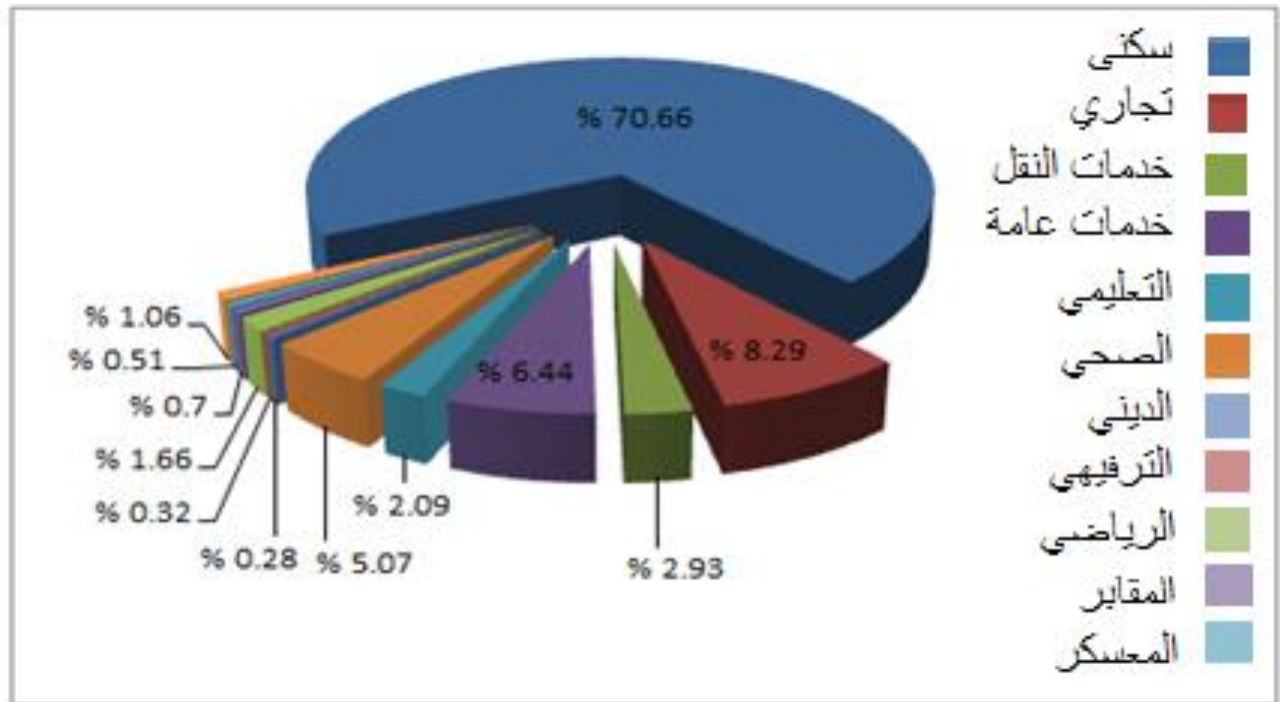

الشكل (4): إستعمالات الأرض الحضرية لمدينة زاخو خاية المرحلة المورفولوجية السادسة عام 2017

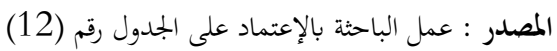

الشكل (4) والجدول (12) يبينان تضاعف الإستعمال وإزدها ر ووصلت المدينة إلى أعلى مستوى لها خلال تاريخ

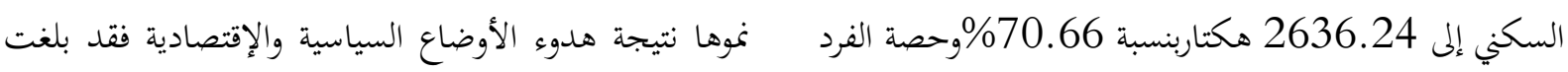

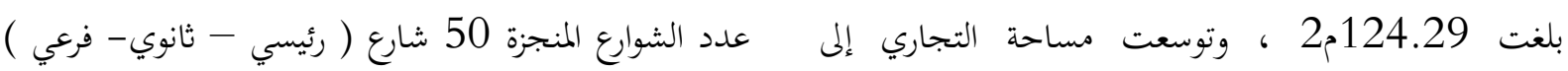

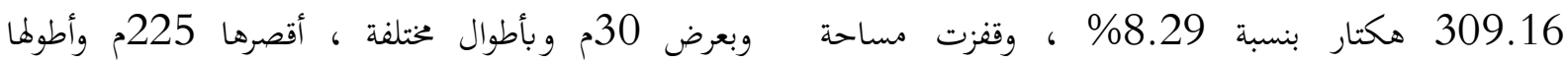

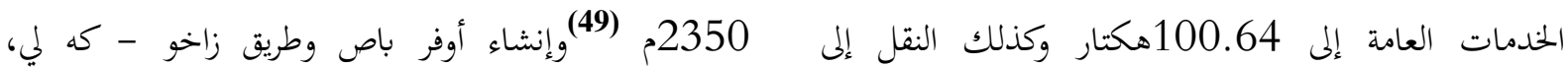

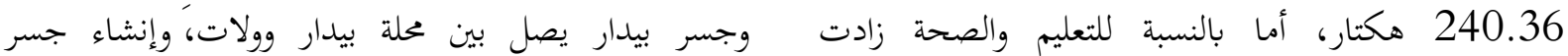

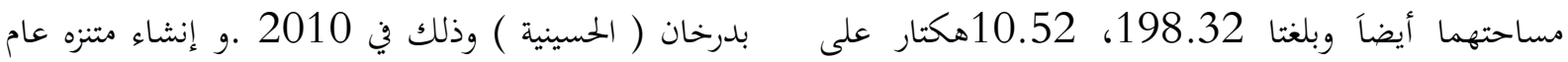

التوالي ، وبعد 2010 حدثت تغيرات كبيرة في مجال الصحة (بارك) في منطقة الصناعة القديمة والحدائق داخل المحلات

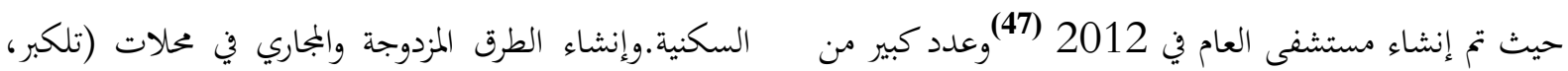

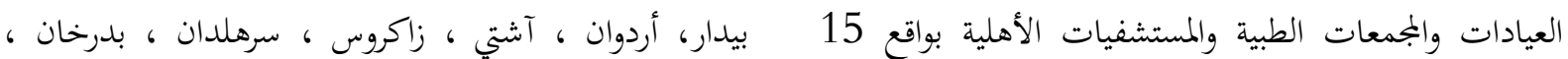

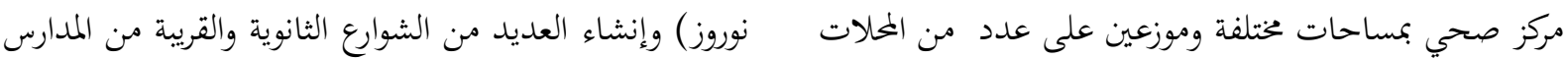

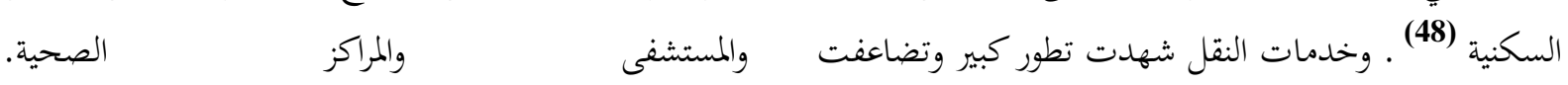
مساحتها إلى 240.36 هكتار حيث كانت فترة إعمار 


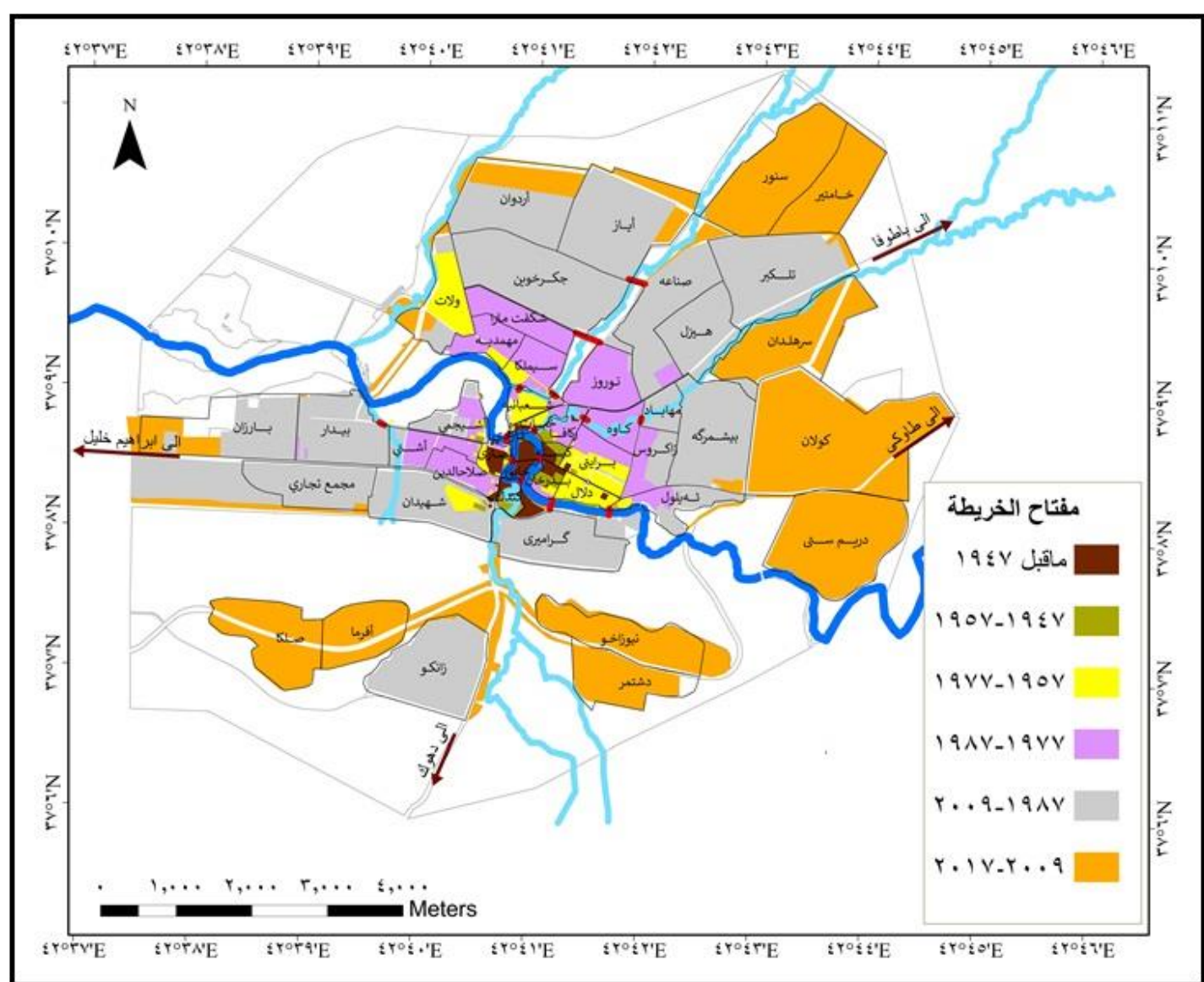

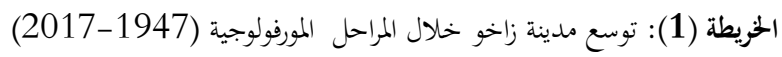

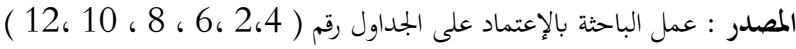




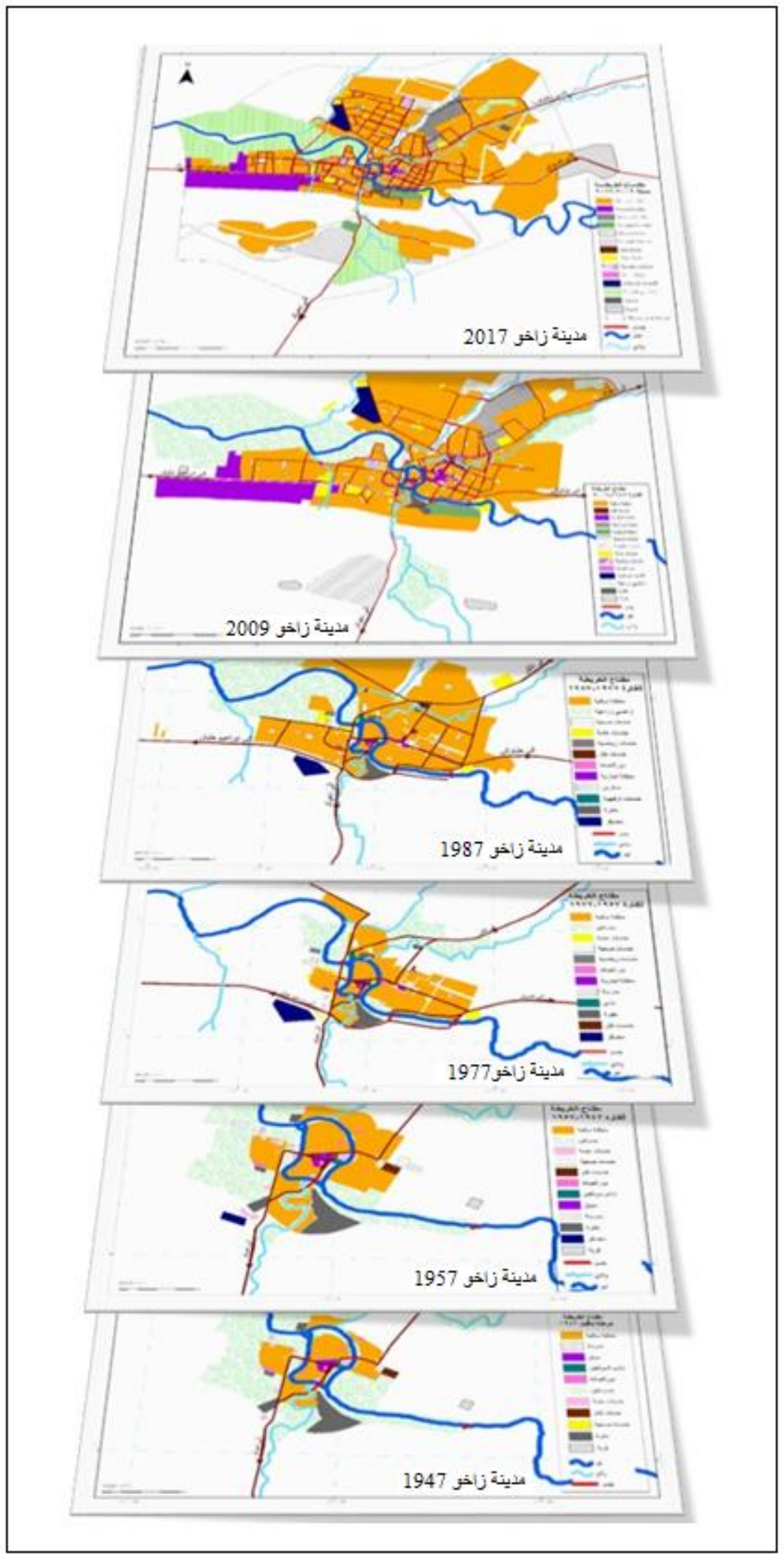

الحريطة (2): إستعمالات الأرض الحضرية في مدينة زاخو خلال المراحل المورفولوجية (1949 - 2017)

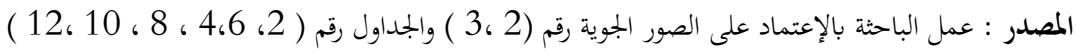


\% من المساحة، ولازالت الإستعمال السكني مستمرة في

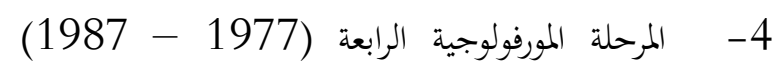
بلغت مساحة المعمور 620.89 هكتار مكونة من 16 محلة سكنية بعدد سكاني (67326) نسمة ، وبكثافة سكانية 129.92 نسمة/هكتار، وبلغت حصة الفرد من المساحة

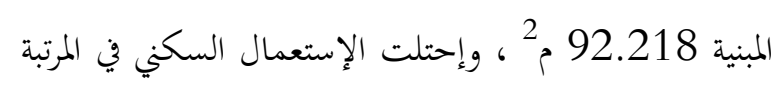

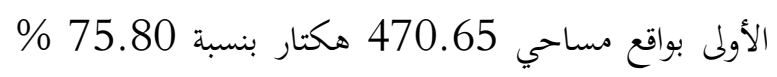
والإستعمال التعليمي في المرتبة الثانية والنقل في الثالثة .

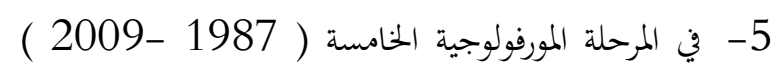
حدثت تغيرات سكانية وعمرانية الكبيرة منها توزيع الأراضي على الشهداء والمعوقين وكوادر الحزب وموظفي الدولة ودمج تلجيج

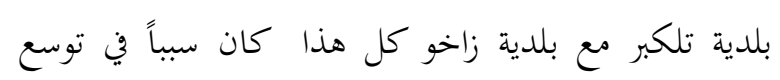
المدينة في كل الإتحاهات وبلغت المساحة 2469.83 هكتار وبواقع سكاني 177626 نسمة وبكثافة 17.57 نسمة الإنكات

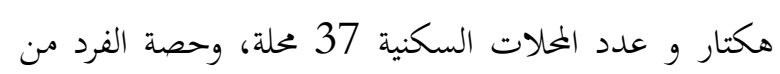

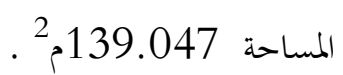

6- المرحلة المورفولوجية السادسة (2009 - 2017 ) رغم قصر فترها الزمنية (8 سنوات) ظهرت 9 محلات جديدة

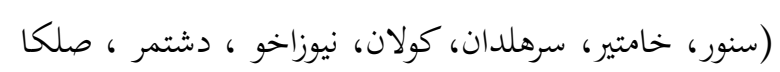

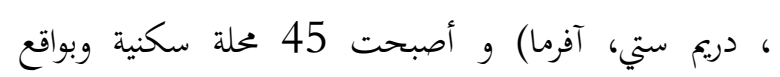
سكاني 234638 نسمة و أن أكبر المحلات مساحة هي وني

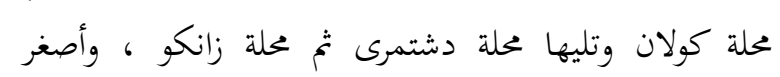

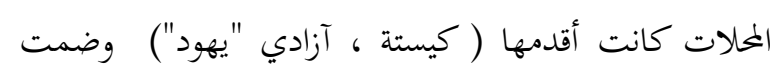

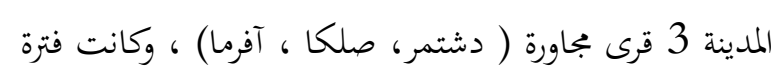

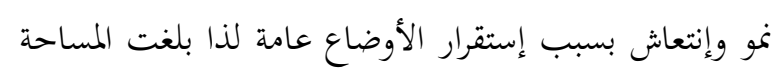

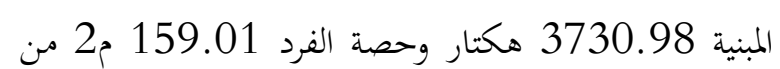

$$
\text { مساحة المعمور . }
$$

7- الملفت للنظر عند تحليل أرقام المراحل المورفولوجية ، أن

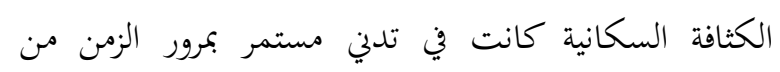
(106 نسمة/هكتار) عام 1947 إلى (56 نسمة/ هكتار)

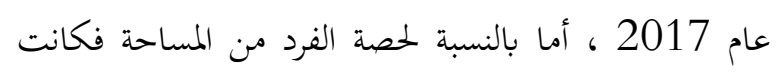

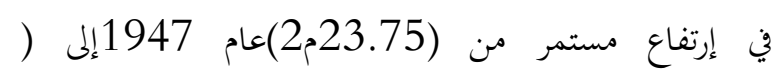

إن إمكانيات منطقة الدراسة الذاتية (الموقع والموضع) كان لمما الدورالكبير في نمو مدينة زاخو وتطورها شكلاً ووظيفة ،

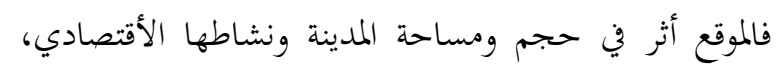

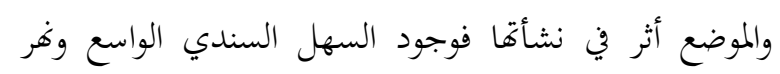

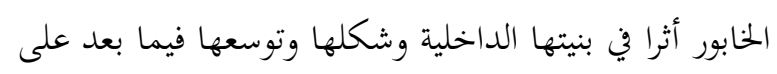

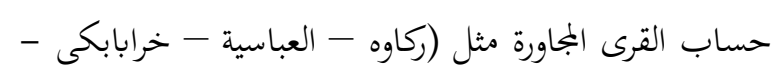

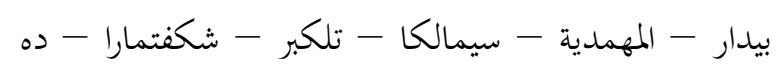
شت مر- آفرما - صه لكا ) خلال مراحلها المورفولوجية (1947-2017) ، وكانت كالتالي: 1- مدينة زاخو ما قبل 1947 كانت بلدة وكانت صغيرة بمساحة

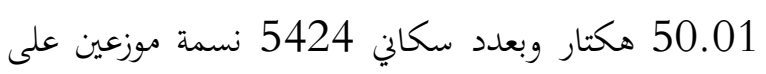
6 محلات سكنية ، وبكثافة 106.876 نسمة/هكتار وحصة الفرد بلغت 23.75²، وإحتلت الإستعمال السكني

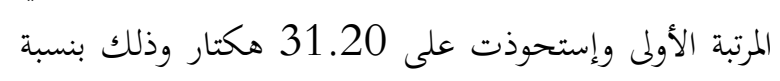

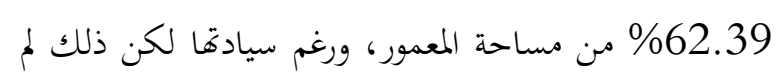
يمنع من قيام بعض المؤسسات الإدارية والخدمية في فترة مبكرة من تاريخ المدينة . 2- في الفترة المورفولوجية الثانية (1947 - 1957) حلميخ . تغيرات على شكل المدينة وسكاها منها (أسر قرية ركاوة ،

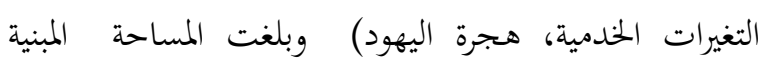

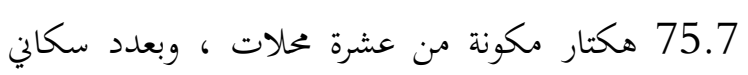

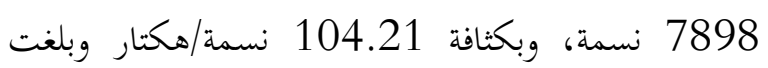
حصة الفرد من المساحة 95.961 م² ، وإحتل الإستعمال السكني المرتبة الأولى بنسبة المكاحة • 52,35 هكتار المبنية 3- في المرحلة المورفولوجية الثالثة (1957 - 1977) كانت الأوضاع السياسية غير مستقرة وتسبب في نزوح الكثير من

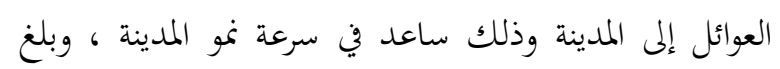
عدد السكان 28526 نسمة عام 1977 يتوزعون في 10 محلات سكنية ، وأصبحت مساحتها 216.56 هكتدار السكان وبكثافة 189.73 نسمة/هكتار وحصة الفرد بلغت 75.9 
بسرعة النمو في السكان والمساحة ، وعدم صحة فرضية عدم التوازن بين السكان والمساحة وفق المؤشرات المستخدمة في الدراسة . البناء الأفقي في أماكن غير صالحة سكنياً التي يتم إختيارها من قبل عامة الناس حسب رغبتهم ، وذلك للحد من سيطرة الإستعمال السكني على الإستعمالات الأخرى بشكل كبير تجنباً للخلل وإنعدام التوازن بين جميع الإستعمالات 3-ضرورة الأخذ بنظر الإعتبار قيم المؤشرات المبينة في الدراسة عن التخطيط لأي توسع مستقبلي لإستعمالات الأرض الحضرية خصوصاً الإستعمال السكني . (11) وصفية مُعجّ شيخو ، المصدر السابق ، ص169

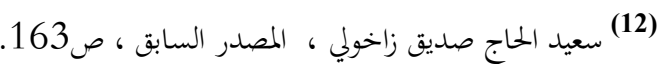

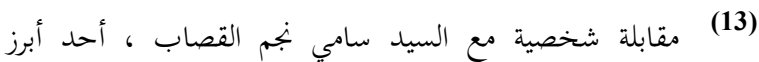

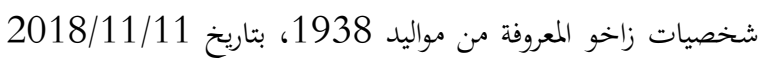

(14) وصفية مُمَّم شيخو ، مصدر سابق ، ص 202- 204 (15)

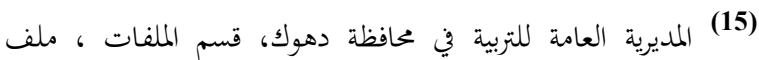

$$
\text { مدرسة الأرمن الإبتدائية رقم } 350 \text { ـ }
$$

(16) سمير محو جميل أحمد ، المواءمة بين خطة مدينة أربيل وكفاءة شبكة رفمة الإندة

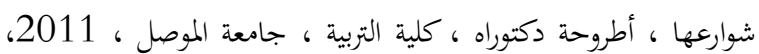

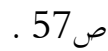

خليل إسماعيل يُمَّمَ ، إقليم كوردستان العراق ، دراسة في التكوين

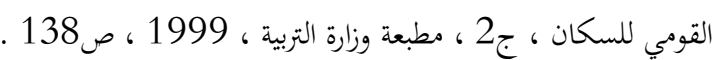

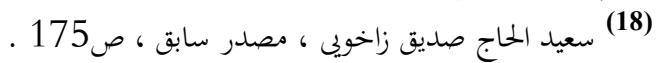

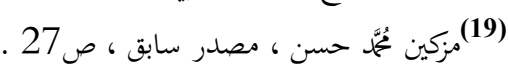

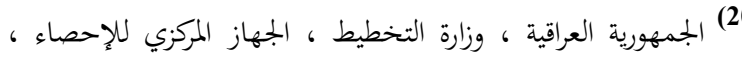

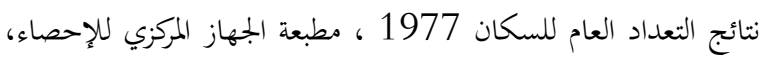
بغداد 1978، ص 330 (21)

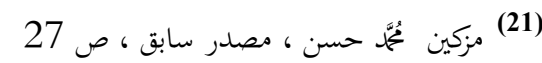

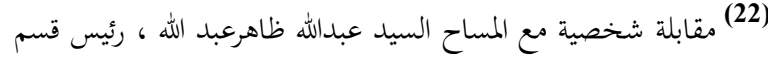

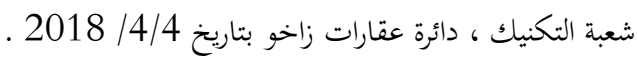

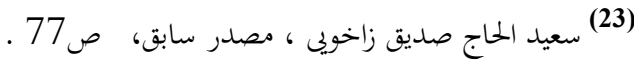

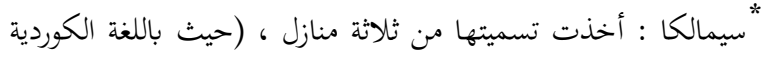
(سى) تعني ثلاثة و(مال) يعني منزل، وتم تثبيت هذا الإسم من قبل فرق
159 12017) عام، أما بخصوص الإستعمال السكني فكانت تتراوح بين (69-75\%) خلال العامين 1947 و2017 على التوالي. وهذا يدل على صحة الفرضية الخاصة على ضوء الإستنتاجات السابقة توصي الدراسة مايلي

1- السيطرة على التوسع العشوائي للإستعمال السكني والذي كان أحد أهم الأسباب الرئيسية في إحداث الخلل في تخطيط الملدينة وتوسعها السريع الغير المنظم ، ووضع الهيئة التخطيطية أمام أمر الواقع من خلال وضع اليد على أراضي كانت مخصصة لإستعمالات أخرى من قبل هيئة التخطيط . 2-التوجه نحو البناء العمودي وذلك بإنشاء عمارات سكنية متعددة الطوابق للإستفادة من المساحات الواسعة التي يشغلها

\section{المصادر و الموامش}

(1) خليل علي مراد ، عبد الفتاح علي البوتاني ،بادينان في سالنامات

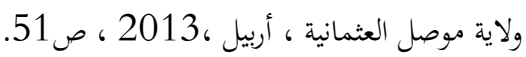

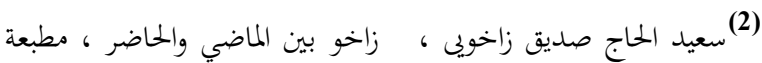

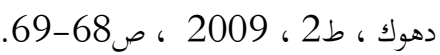
(") القصبة : تعني المدينة وكذلك القرية ( بجد الدين بن عُمَّمَ بن يعقوب الفيروز ابادي ، معجم القاموس المحيط ، منشورات دار الحديث ، القاهرة ، 2008 ، ص1328 والقصبة : قصبة القرية وسطها وقصبة السواد مدينتها ، وهذا بعني أن منطقة زاخو قصبتها مدينة زاخو ( مُعَّمَ بن أبي

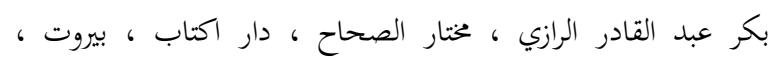

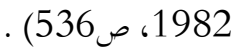

(*) منزخانة - تعني نزل لسعاة البريد (مكان إستراحة ساعي البريد)

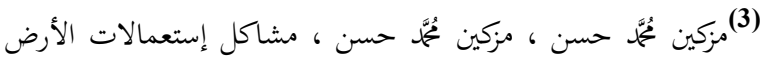

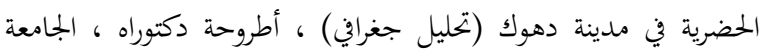

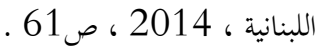
خليل علي مراد ، عبد الفتاح علي البوتاني ، بادينان في سالنامات

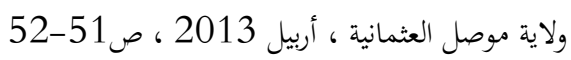

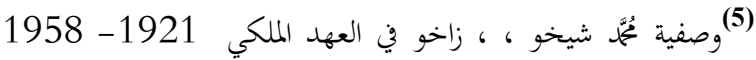
دراسة تاريخية في أوضاعها العامة مصدر سابق ، ص 266- 268

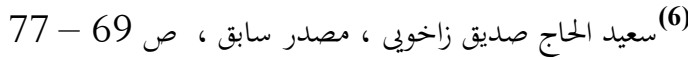
(7) جريدة فتى العراق ، العدد 205 ، 23 أيار 1957. (8) سعيد الحاج صديق زاخولي ، المصدر السابق ، ص 159.

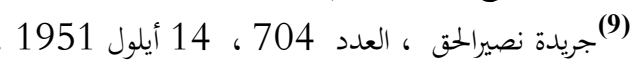

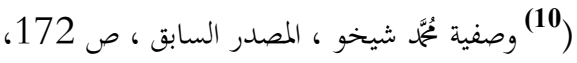


(38) مقابلة شخصية مع المساح السيد رضوان خير الله قاسم ، رئاسة

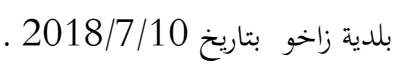

(39) مقابلة شخصية مع السيد نريمان صديق سليمان مبرمج في قسم

IT

2018/7/9

(40) مقابلة شخصية مع المساح السيد عبدالله ظاهرعبد الله ، رئيس

قسم شعبة التكنيك ، دائرة عقارات زاخو بتاريخ 2018 / 2014

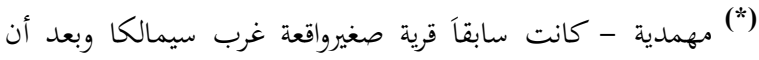

أصبحت قرية سيمالكا محلة من محلات زاخو ضمت معها قرية المهمدية

وبقيت إسمها متداولة محلياً ولكن في الإحصاءات الرسمية تذكر فقط محلة سيمالكا . فهو إسم قديم ومتداول جداً مر ءحليا ولكن ظهور الإسم

$$
\text { رسمياً حديث العهد }
$$

مقابلة شخصية مع المساح السيد رضوان خير الله قاسم ، رئاسة

(41)

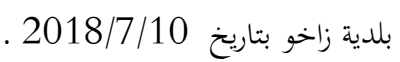

مقابلة شخصية مع المساح السيد عبدالله ظاهرعبد الله ، رئيس قسم

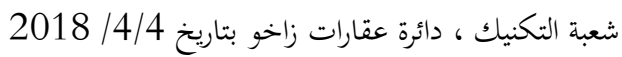

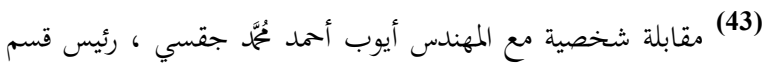

أجازات البناء في رئاسة بلدية زاخو بتاريخ 10/30/ 2019 .

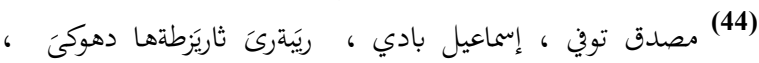

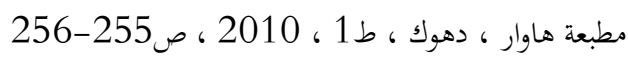

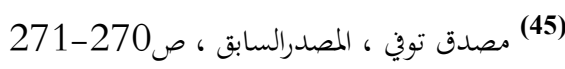

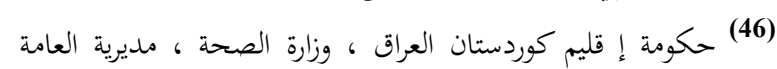

لصحة دهوك ،مديرية صحة زاخو.

(47) حكومة إقليم كوردستان العراق ، وزارة الصحة ، مدية مديرية العامة

لصحة دهوك ، مديرية صحة زاخو ، شعبة المهندسين إنموردين

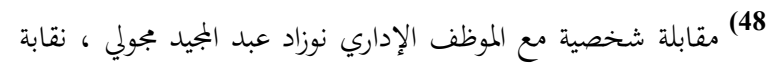

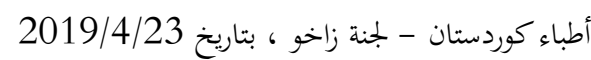

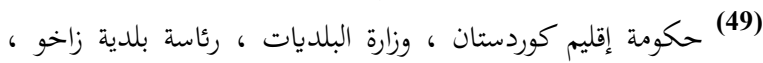

$$
\text { القسم الفني ( بيانات غير منشورة) . }
$$

رش المبيدات آنذاك وكان عليهم ترقيم الدور والمحلات كخطة عمل لإنجاح الحملة والتي كانت القرية بجرد ثلاثة بيوت وبدون إسم ـ

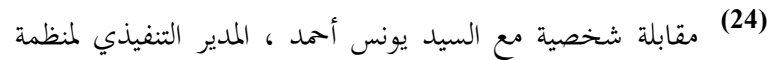
فرشين لحماية البيئة ، بتاريخ 2019/5/26

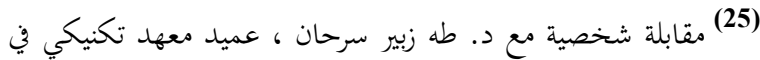

زاخو ، كان معاون شؤون فنية ومسؤول حقول في إعدادية الزراعة

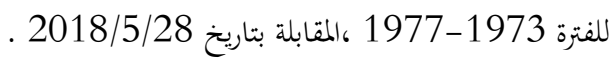

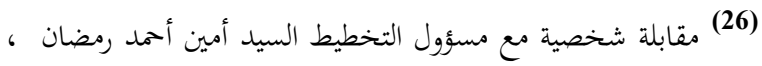
مديرية تربية زاخو ، قسم التخطيط ، 2018/12/18

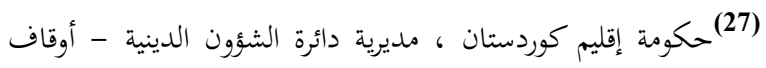

$$
\text { زاخو ، قسم المساجد . مقابه }
$$

(28) مقابلة شخصية مع السيد يونس أحمد ، المدير التنفيذي لمنظمة ، ماحس ،

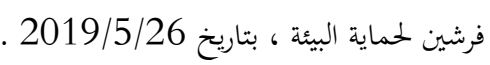

(29) مقابلة مع السيد سامي نجم القصاب ، مواليد 1938 بتاريخ

2018/11/11

2019/5/26 مقابلة مع السيد سعيد رزفان زاخولي بتاريخ

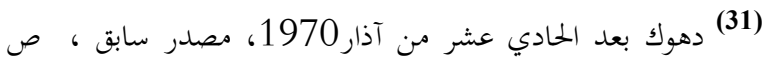

. $291-286$

مقابلة شخصية مع السيد سامي نجم القصاب بتاريخ

2018/11/11

(33) حكومة إقليم كوردستان ، مديرية تربية زاخو ، قسم التخطيط .

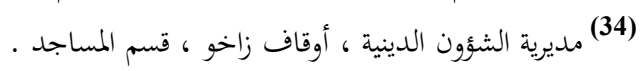

(35) مقابلة شخصية مع المساح السيد عبد الله ظاهر، دائرة عقارات

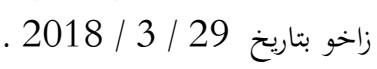

(36) مقابلة مع السيد المساح عبدالله ظاهرعبد الله ، دائرة عقارات

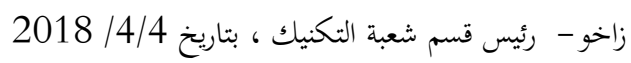

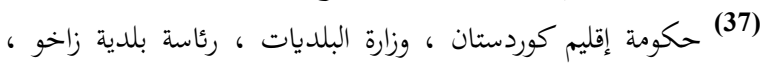

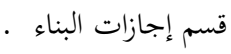


يِيشكه فتنا يهيوهنديا دناقبهرا ئهردى نيّشتهجيِبوونى و ئاكنجييّن (نيشتهجيِين) بازيّريّ زاخو ل دويف

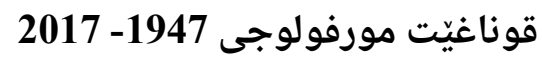

يوخته

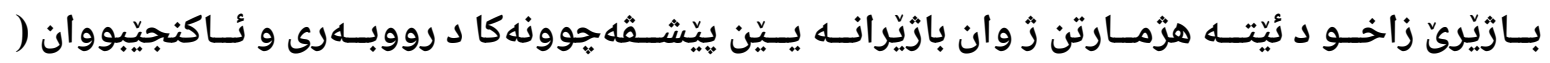

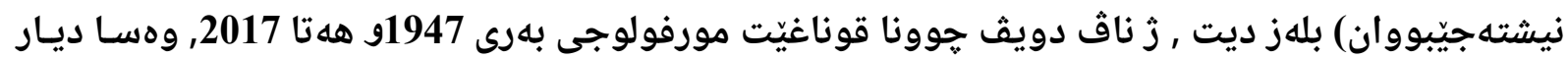

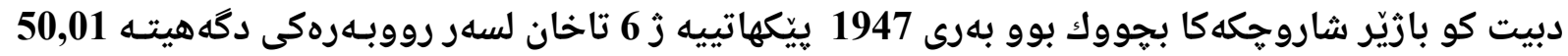

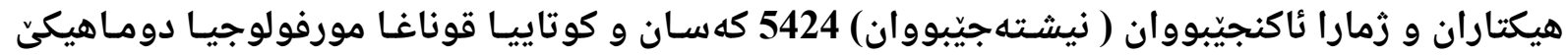

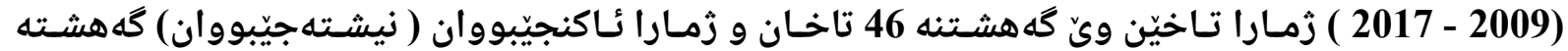
234638 كهسان , د رووبهرهكى دگه هيته 3730,98 هيكتاران .

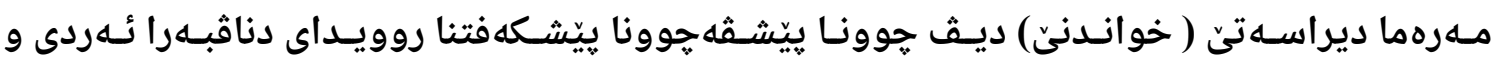

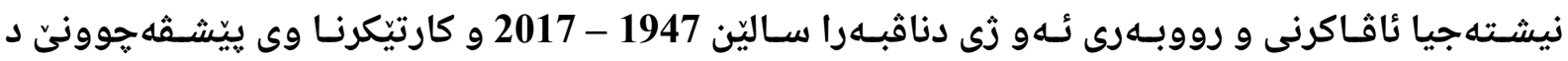

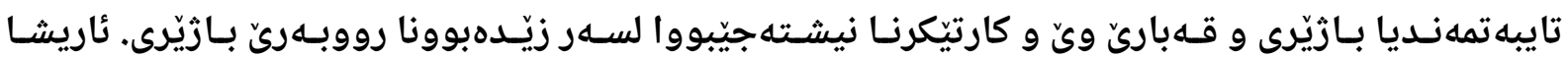

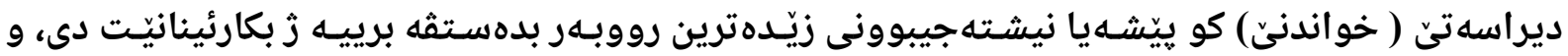

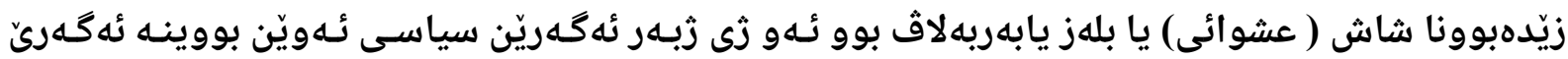

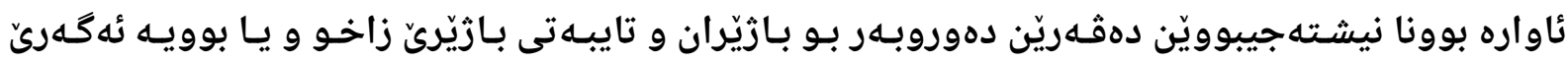

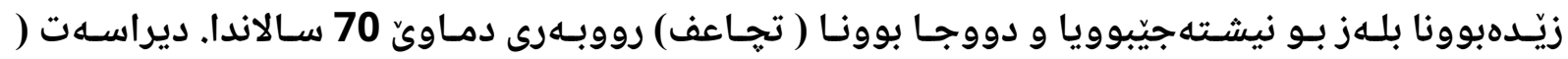

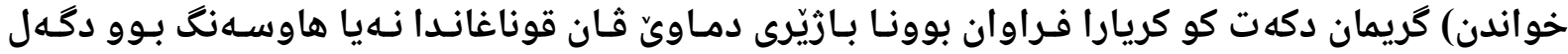

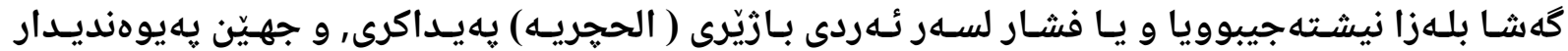
نهجاركرييه بو وهبهرهينانا ئهردي نه گونجاى بو بكارئينانا بازيرى.

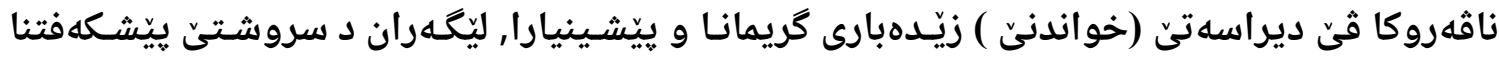

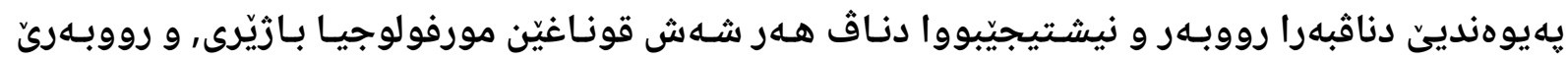

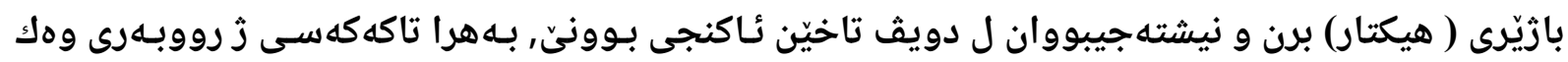

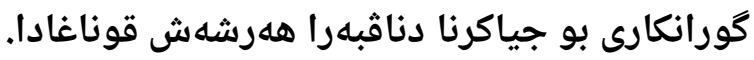

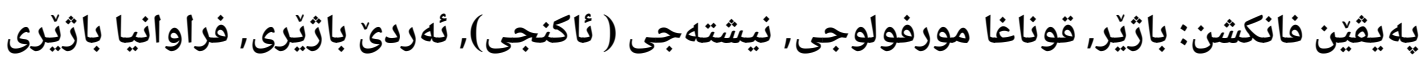




\title{
THE DEVELOPMENT OF THE RELATIONSHIP BETWEEN LAND USE AND INHABITANTS OF ZAKHO ACCORDING TO URBAN MORPHOLOGY STAGES FROM 1947 TO 2017
}

\author{
NASHWAN SHUKRI ABDULLAH and JIHAN HASHEM MOHAMMED \\ Dept. of y Geography, College of Humanities Science, University of Duhok, Kurdistan Region-Iraq \\ Dept. of y Geography, College of Education, University of Zakho, Kurdistan Region-Iraq
}

\begin{abstract}
Zakho is considered one of the cities that has witnessed a rapid growth in area and population during urban morphological stages from 1947 to 2017. Prior to 1947, Zakho was a very small place that has six residential units with the area of 50.01 hectares and a population of only 5424 people. On the other hand, in the final stages of urban morphology (2009-2017), the number of the residential units reached 46 and the population peaked at 234638 people on area of 3730.98 hectares.

This study aims to showcase the relationship between land use in terms of urbanization and area during $1947-2017$ and the effects of this development on the characteristics of the city. Similarly, it focuses on the impact of the growth of the population on the area of the city. The problem of study is that the greatest deal of the area is used for urbanization and building than for other uses. The random urban growth was the lead reason because of the political situations which obliged a lot of families from the vicinities of Zakho to come and settle in the city. It can be observed that the urban growth was multiplied in the past 70 years. It is hypothesized that the city urban growth during these stages was not aligned with the growth of the population which created a pressure on the area of the city. This led governmental and private sectors to use unqualified lands and areas for other social purposes and infrastructures.

The study is consisted of introduction, hypotheses, and results. It studies the nature of the development of the relationship between land use and inhabitants of Zakho according to urban morphology stages. The empirical data were taken in hectares and according to the number of the residential units and population density. The individual space was taken as a variable to distinguish among the six stages.
\end{abstract}

Keywords: City, Urban Morphology, Population, Urban Land Use, Urban Growth 